NBER WORKING PAPER SERIES

\title{
BABY BUSTS AND BABY BOOMS: \\ THE FERTILITY RESPONSE TO SHOCKS IN DYNASTIC MODELS
}

\author{
Larry E. Jones \\ Alice Schoonbroodt \\ Working Paper 16596 \\ http://www.nber.org/papers/w16596
NATIONAL BUREAU OF ECONOMIC RESEARCH
1050 Massachusetts Avenue
Cambridge, MA 02138 \\ December 2010
}

The authors thank the National Science Foundation, Grant SES-0962432, and the ESRC Centre for Population Change for financial support. We also thank Michele Boldrin, V.V. Chari, Simona Cociuba, Martin Gervais, David Hacker, John Knowles, Ellen McGrattan, Thomas Sargent, Henry Siu, Michele Tertilt for helpful comments. The views expressed herein are those of the authors and do not necessarily reflect the views of the National Bureau of Economic Research.

NBER working papers are circulated for discussion and comment purposes. They have not been peerreviewed or been subject to the review by the NBER Board of Directors that accompanies official NBER publications.

(C) 2010 by Larry E. Jones and Alice Schoonbroodt. All rights reserved. Short sections of text, not to exceed two paragraphs, may be quoted without explicit permission provided that full credit, including (C) notice, is given to the source. 
Baby Busts and Baby Booms: The Fertility Response to Shocks in Dynastic Models Larry E. Jones and Alice Schoonbroodt

NBER Working Paper No. 16596

December 2010

JEL No. E13,J11,J13,O11

\begin{abstract}
$\underline{\text { ABSTRACT }}$
Economic demographers have long analyzed fertility cycles. This paper builds a foundation for these cycles in a model of fertility choice with dynastic altruism and aggregate shocks. It is shown that under reasonable parameter values, fertility is pro-cyclical and that, following a shock, fertility continues to cycle endogenously as subsequent cohorts enter retirement. Quantitatively, in the model, the Great Depression generates a large baby bust -- between $38 \%$ and $63 \%$ of that seen in the U.S. in the 1930s -- which is subsequently followed by a baby boom -- between $53 \%$ and $92 \%$ of that seen in the U.S. in the 1950s.
\end{abstract}

Larry E. Jones

Department of Economics

University of Minnesota

4-101 Hanson Hall

1925 Fourth Street South

Minneapolis, MN 55455

and NBER

lej@umn.edu

Alice Schoonbroodt

University of Southampton

School of Social Sciences

Economics Division (58 Murray, Room 3013)

Highfield, Southampton SO17 1BJ

United Kingdom

alicesch@soton.ac.uk 


\section{Introduction}

Fertility rates in the U.S. varied dramatically over the 20th century. During the first part of the century, they continued a drop, begun in the mid 19th century, that demographers associate with the Demographic Transition. Total Fertility Rates (TFR) fell from 5.7 children per woman to 3.0 over the period from 1850 to 1925 . In the years that followed there was an even more abrupt drop during the years of the Great Depression, from 3.0 to 2.1. Indeed, women in their prime fertility years during the Great Depression had, on average, only 2.2 children in their entire lifetime. These women, born between 1905 and 1915, had fewer children than any previous cohort (in fact, fertility did not go back down to those levels until the 1970s). Following this, fertility rebounded significantly during the 1950s and early 1960s, the Baby Boom. At its peak, TFR reached 3.6 while Cohort Total Fertility (CTFR) showed a similar, but smaller, increase up to 3.2 .

One of the key hypotheses put forward by economic demographers for these large and opposite swings is known as the 'Easterlin hypothesis', see Easterlin (1961, 1968, 1978, 1987). In a nutshell, the idea behind this hypothesis is that fertility was exceptionally low during the Great Depression because of the large negative shock to incomes. Then, in substantial part, due to the fact that fertility had been so low during the 1930s, the Baby Boom occurred. The mechanism through which low fertility in the past leads to high fertility one generation later has usually been attributed to the feedback effects of the resulting unbalanced age-structure on relative wages of young fertile workers to older workers in combination with differences between expected lifetime income relative to 'material aspirations formed in childhood.'

In this paper, we build a model of fertility choice combining features of a stochastic growth model with a model of fertility choice with dynastic altruism à la Barro-Becker (Becker and Barro, 1988, and Barro and Becker, 1989). ${ }^{2}$ In addition to the stochastic component, the model extends existing Barro-Becker type models to include multiple periods in the working life. For simplicity, we assume that labor is the only factor of production (except in Section 5.3) and that different age-groups are perfect substitutes in production (up to agespecific productivity levels). Thus, we abstract from feedback effects of relative cohort sizes

\footnotetext{
${ }^{1}$ The so called 'Easterlin hypothesis' has developed over Easterlin's own work and has been interpreted in more than one way by other authors along the way. For an excellent overview until 1998, see Macunovich (1998). She 'focuses just on the fertility aspects of the Easterlin hypothesis', which is our focus as well. For a more general overview, see Macunovich and Easterlin (2008).

${ }^{2}$ Some have put forth the idea that the baby boom was a consequence of low fertility during the Great Depression - i.e., the baby boom was 'catching up.' However, completed fertility (CTFR) was low for both the women immediately preceding and immediately following the baby boom and hence, this cannot be true at the level of the individual mother. It can, in principle, hold across cohorts in a dynastic model. This distinction is relevant in our analysis and is one of our motivations for studying a dynastic model.
} 
on relative wages. In this model, we study, both qualitatively and quantitatively, fluctuations in fertility, triggered by (large) income shocks using preference parameter configurations in line with the standard growth and business-cycle literatures.

We show that both of the effects originally discussed by Easterlin, the large reactions of fertility to large income shocks, and the oscillations thereafter, are present in the model (despite the absence of feedback effects through wages). In particular, we find that fertility is procyclical as long as most of the costs of children are in terms of goods, or as long as there is sufficient curvature in the period utility function. On top of this, the policy function for current fertility as a function of past fertility that comes out of our model is negatively sloped around the steady state. We find that that the dynamics of adjustment following a movement off a balanced growth path is one of dampened oscillations. Putting these two effects together, in the model, a large negative income shock is met with a contemporaneous reduction in fertility followed by a baby boom a generation later. Thus, in the model the Great Depression would trigger a baby bust, followed by a baby boom a generation later.

In our model, children are partly a consumption good (Barro-Becker preferences) and partly an investment good (future labor force) for the dynasty. Comparing our results with those standard in growth models gives substantial intuition. The role of the capital stock(s), is played by the age distribution of the population, while the number of births plays the role of investment. Then, as is standard in growth models (for standard consumption smoothing reasons), periods when productivity is particularly high are times when investment is high. Here this translates to: fertility is high during periods of high productivity - an income boom generates a baby boom. Correspondingly, an income bust generates a baby bust. In addition, the larger is the desire to smooth consumption, the larger the elasticity of fertility to income shocks. There is one subtlety that needs to be added with this interpretation. This is that, when the cost of a new child is primarily in terms of time, good times are both good times to save for the future (invest) and times when that investment is most expensive. As a result, in this case, fertility is only procyclical when there is sufficient desire to smooth consumption (i.e., more curvature than log utility). ${ }^{3}$

A similar intuition gives us insight as to why the model exhibits dampened oscillations. This has to do with the specification of the implicit depreciation rates of the age-specific populations. When the stock is the number of people, the counterpart of depreciation is movement out of the work force. Thus, fertility (i.e., investment) will be higher in periods

\footnotetext{
${ }^{3}$ Notice that one important feature here is that income is temporarily high or low, relative to trend. As shown by Jones and Schoonbroodt (2010), a permanent increase in productivity growth has a permanent negative effect on fertility under the parameter values that generate pro-cyclical fertility here. Thus, the important distinction between temporary and permanent changes in productivity shocks is just as important here as it is in standard growth and business cycle models.
} 
when a relatively large share of workers are nearing retirement age. Because of this effect, a baby bust now means that the next generation's workforce is primarily older workers - more workers will be retiring. Consequently, investment will be higher in response - a baby boom will occur.

On the quantitative side, we use a calibrated version of the model to simulate the size of the response of fertility to productivity shocks, both contemporaneous and delayed. After calibrating to U.S. averages, we find that the contemporaneous response to a 1 percent deviation in productivity lies in the range of 1 to 1.7 percent depending on the nature of the costs of children (generally, responses are smaller when the costs of children are primarily in terms of parental time) while the elasticity one period later lies between 0.94 and 1.5. This implies that the response of (completed) fertility to a 'standard recession' (say, productivity is 5 percent below trend for 2 years) is relatively small - of the order of 0.02 to 0.04 children per woman with a subsequent baby boom of similar size. However, we find that the reduction in fertility implied by the model as a response to the 12 percent decrease in productivity during the Great Depression is between 38 and 63 percent of the observed pre-WWII baby bust in Total Fertility Rates (TFR). Moreover, the subsequent endogenous fluctuations in fertility triggered by this bust, in conjunction with the productivity boom in the 1950s and 1960s, captures between 53 and 92 percent of the post-WWII baby boom in TFR. ${ }^{4}$

Since both the Depression and the Baby Boom are phenomena that occurred in many different countries, we go on to study one obvious implication of our model. If the mechanisms that we study are important, it should be true that countries that had deeper depressions in the 1930s should also have larger baby busts in the 1930s, and that those with larger baby busts should experience larger baby booms in the 1950s. In Section 6, we show that this is indeed true, conditional on the economic circumstances in the 1950s. These observations further support our theory.

Many other demographers and economists have studied fluctuations in fertility but they have focused on different channels. First, operationally, the mechanisms that are the driving forces behind our results are considerably different than those emphasized by Easterlin in his work. For example, he emphasizes differences between expected lifetime income relative to 'material aspirations formed in childhood.' Here, the basic mechanisms are best understood as variants of standard effects of growth models - the desire to smooth consumption, etc. ${ }^{5}$

Second, following Easterlin many authors have analyzed the dynamics of age-structured

\footnotetext{
${ }^{4}$ Realistically, it seems unlikely that fertility decisions are affected by quarter to quarter fluctuations in productivity (as addressed in the business cycle literature). This is consistent with our quantitative findings. Rather, a prolonged boom or bust is required for the fertility effect to be large.

${ }^{5}$ Feichtinger and Dockner (1990) assume a positive relationship between births and the difference between actual and expected consumption, which is more in line with Easterlin's original argument.
} 
populations that results when it is assumed that the relationship between fertility today and past fertility has a negative slope, see Lee (1974) and Samuelson (1976) for early analysis of dynamic population systems of this kind. ${ }^{6}$ In contrast, we provide a choice-theoretic foundation for these cycles.

Third, we assume that different ages of workers are perfect substitutes in production. Nevertheless, fertility cycles are generated through the curvature of preferences. This shows that feedback effects from the age-structure on wages are not necessary to generate population cycles. This is an alternative to Easterlin's feedback effect which, as suggested by Lee (2008), can be generated by using a CES production specification, where different age-groups are not perfect substitutes.

Further, the mechanisms that we highlight here are also complementary to those explored in other papers that have used choice-theoretic dynamic macroeconomic models to study the Baby Boom. Three key examples are Greenwood et al. (2005), Doepke et al. (2007) and Albanesi and Olivetti (2010). In Greenwood et al. (2005), the channel that is highlighted is the effects of the drastic improvement in technologies of home production that took place in the post WWII period. In essence, these improvements temporarily made having children cheaper generating the boom. In Doepke et al. (2007), they emphasize the relatively high female participation rate that took place during WWII. This, because of learning on the job, made that specific cohort of women relatively high productivity. Because of this, the cohort of women entering their 20s in the 1950s faced a relatively tough job market causing them to delay entering the workforce and have larger than normal families. Albanesi and Olivetti (2010) emphasize the decrease in maternal mortality as a cause of the baby boom. This decrease in mortality also increased the incentive to invest in human capital, triggering the return to low fertility in the 1970s. Thus, the primary channels emphasized in those papers differ from ours. One advantage of our approach is that it is also able to capture the sizeable downward movement, relative to trend, in fertility in the 1930s.

Finally, our findings can rationalize the observations in Butz and Ward (1979) as follows. In brief, they find that fertility, while procyclical, has become less responsive to business cycle frequency fluctuations over time. In our model, this can happen for two reasons. The first comes from the fact that the size of the effects that we find are smaller when the costs of children are in terms of time. Since there has been a large increase in labor force participation among married women, this causes the time cost of children to be increasingly important. Second, due to continuing fluctuations triggered by the Great Depression, the fertility response to productivity shocks is mitigated. In our data analysis, we show that,

\footnotetext{
${ }^{6}$ Feichtinger and Sorger (1989) extend Samuelson's initial model to continuous time.
} 
controlling for productivity shocks in the past is crucial to find a positive correlation of fertility with contemporary shocks. It is yet to be seen how large the fertility response to the most recent recession will be, though it does go in the direction predicted by the theory (see, for example, Sobotka et al., 2010).

In Section 2 we review the data for the U.S. since 1900. The model is laid out in Section 3 and the analytic results are presented. In Section 4, we explore the quantitative implications of a calibrated version of the model compared to U.S. data. In Section 5 we study the sensitivity of our results to some basic changes in our assumptions. Finally, we present international evidence in Section 6 while Section 7 concludes.

\section{U.S. data}

In this section, we lay out the basic facts about the time paths of productivity and fertility in the U.S. over the 20th century. We begin with the facts pertaining to the growth in productivity using a consistent measure for total factor productivity (TFP) and labor productivity (LP) from Chari et al. (2007). As most economists know, this period is one of more or less continued growth in productivity with a few interruptions. The most significant of these is the Great Depression. Figure 1 shows the natural logarithms of TFP and LP over the period from 1901 to 2000.

The facts about productivity over this period can be described as follows:

1. the continual upward trend;

2. the marked decline below trend that took place in the 1930s and early 1940s;

3. the return to trend in the early 1950s;

4. the significant increase above trend that took place in the 1950s and 1960s;

5. the productivity slowdown since the 1970s.

This timing of the movements of productivity around trend fits well with the movements in fertility seen in the data. Figure 2 shows the time path of the Total Fertility Rate (TFR) and Cohort Total Fertility Rates (CTFR) (by birthyear of mother +23 years) over the period from 1850 to 2000. We have two time series for TFR, which calculates how many children a woman would have over her lifetime if current age-specific fertility rates were to prevail in the future. The first series is the one prepared by Haines (1994) using Census data and hence is available only every 10 years. The second comes from the Natality Statistics Analysis from National Center for Health Statistics. It is available at annual frequencies, but only since 1917. The CTFR series comes from Jones and Tertilt (2008) and counts how many children 
Figure 1: Total Factor Productivity and Labor Productivity, 1901-2000 (1929=100)

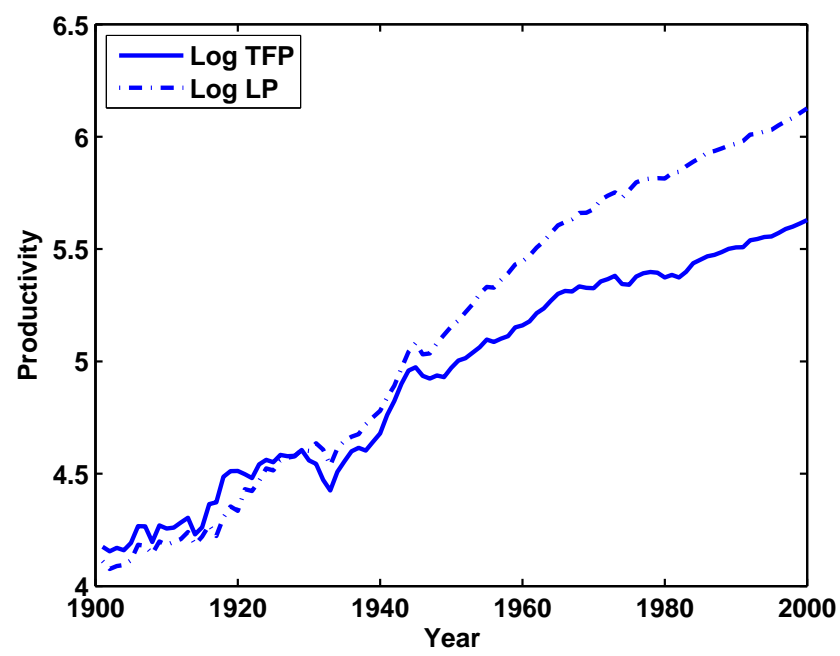

were born to a particular cohort of women at the end of their fertile period. Implicitly, it is equivalent to adding age-specific fertility rates pertaining to a particular cohort of women over time. Its frequency is five-year birth cohorts.

At the beginning of the period, fertility is still in the midst of what is known to demographers as the demographic transition, the marked fall in fertility (and mortality) that has occurred in all developed countries. This fall accelerates from the late 1920s to the mid 1930s. Fertility then increases to reach its peak in the baby boom of the 1950s and 1960s. It appears that a good description would be:

1. high, and fairly constantly decreasing fertility from 1850 until 1925, when it reaches a TFR of about 3.0 children per woman;

2. an acceleration of the rate at which fertility is falling between 1925 and 1933 (from $\mathrm{TFR}=3.0$ to $\mathrm{TFR}=2.1$;

3. constant, but low, fertility over the period from 1933 to 1940 , with the level at about $\mathrm{TFR}=2.2$;

4. rapidly rising fertility from 1940 to 1957 , with TFR going from 2.2 up to 3.7;

5. high, stable fertility from 1957 to 1961 at about $\mathrm{TFR}=3.6$;

6. a rapid decrease from 1961 to 1976 , with TFR going from 3.6 down to 1.7;

7. a slight increase and then stable low fertility over the remainder of the period, with the level at about $\mathrm{TFR}=2$. 
Figure 2: (Cohort) Total Fertility Rate, 1850-2000

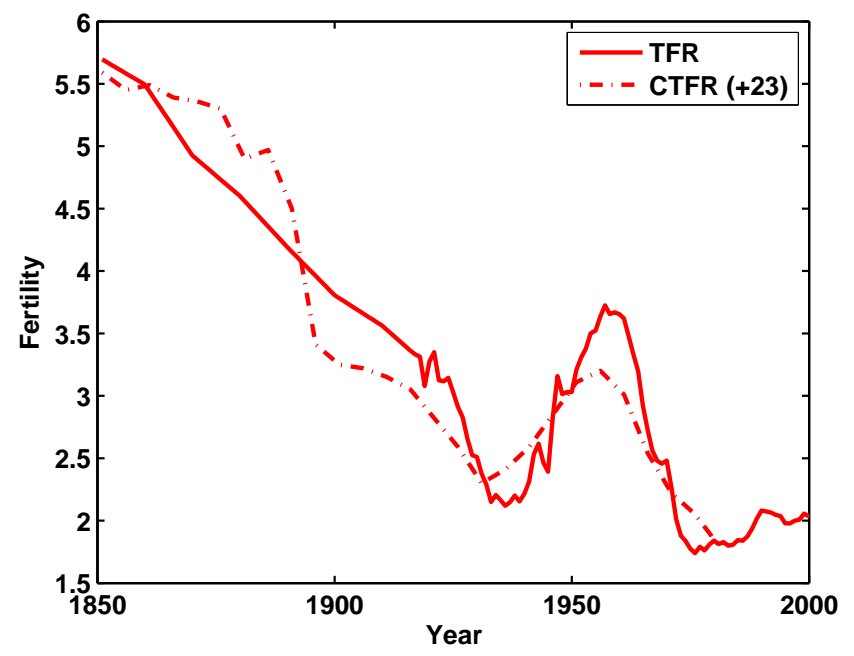

We will refer to 2 and 3 as the pre-WWII baby bust, 4 and 5 as the post-WWII baby boom and 6 as the baby bust of the 1970s. The exact sizes of these features of the data depend on how one treats the trend growth in productivity and trend decrease in fertility over the period. For example, was there a common, exogenous growth rate in productivity over the entire period with higher frequency (albeit highly autocorrelated) fluctuations around this trend? Or, were there several regimes of growth? For fertility, one can see that while TFR decreases smoothly over time, the early CTFR data shows that the largest decrease happens for cohorts of women born between 1858 (4.9 children per women) and 1878 (3.25 children per woman). The fluctuations thereafter, however, look very similar in both series, though somewhat larger in TFR than CTFR.

For fluctuations, we fit a linear trend to the (ln) TFP and LP series from 1901 to 2000 (ln $P_{t}=\alpha_{0}+\alpha_{1} t+\epsilon_{t}$, where $\left.P=\{T F P, L P\}\right)$, and detrend TFR using an HP filter (smoothing parameter, $w=20,000$ ). We obtain annual percent deviations over this period plotted in Figure 3. Several alternative detrending methods were studied with very similar results.

Although it is not perfect, there is an impressive coincidence in timing. The coefficient of correlation between annual TFP and TFR deviations for the years 1901 to 2000 is 0.4, with a coefficient of 0.71 from 1901 to 1940 and a correlation of 0.2 from 1941 to 2000. This suggests that the U.S. TFR is procyclical during the early time period but the correlation is much weaker thereafter (see also Butz and Ward, 1979). As suggested by the model below, one reason for the decrease in the correlation may be the increase in female labor supply 
Figure 3: TFR, TFP and LP Percent Deviations From Trend, 1901-2000

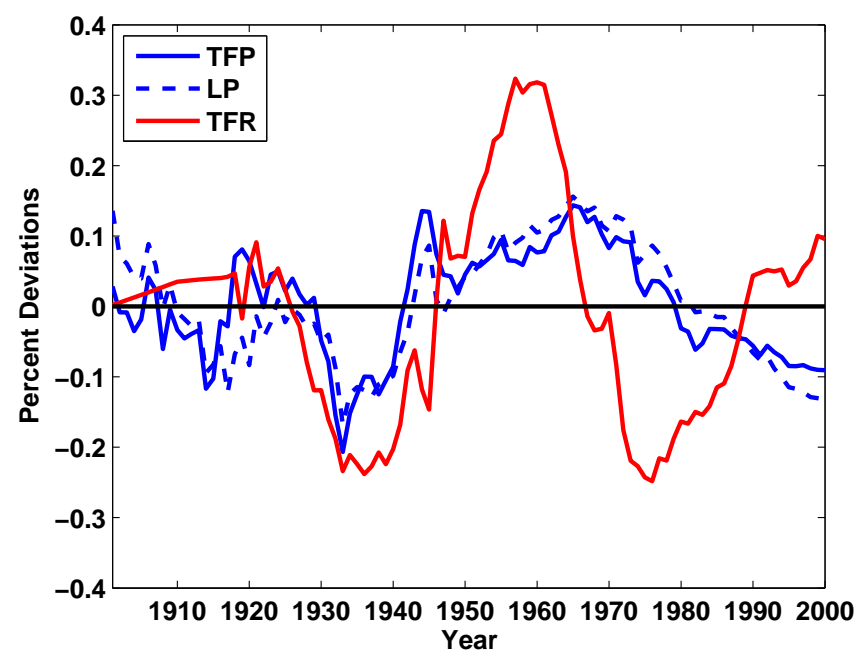

which made the opportunity cost of children, women's wages, procyclical.

What our model simulation is also going to capture is the large downward deviation in the 1930s due to the large negative shock during the Great Depression and a baby boom following endogenously as a response to the baby bust itself, one generation later. We therefore also run the following regression. Let $\widehat{X}_{t}$ denote the percent deviation from trend in variable $X$ in period $t$.

$$
\widehat{T F R}_{t}=\lambda_{0}+\lambda_{1} \widehat{P}_{t}+\lambda_{2} \widehat{P}_{t-l}+\varepsilon_{t}
$$

where $P=\{T F P, L P\}$ and $l \in\{20, \ldots, 25\}$. The results for $l=20$ are given in Table 1 . Similar results go through for larger values of $l$.

Table 1: U.S. TFR and Productivity: Regression results

\begin{tabular}{l|l||l|l}
\hline \hline Indep. Var. & Coefficient & Indep. Var. & Coefficient \\
\hline Constant & -0.0051 & Constant & -0.0058 \\
$\widehat{T F P}_{t}$ & $0.8363^{* *}$ & $\widehat{L P}_{t}$ & $0.6004^{*}$ \\
$\widehat{T F P}_{t-20}$ & $-0.8401^{* *}$ & $\widehat{L P}_{t-20}$ & $-0.6218^{*}$ \\
\hline \hline
\end{tabular}

*, **: Significantly different from zero at $5 \%$ and $1 \%$, respectively.

These regressions show that the coefficients on contemporaneous productivity $\left(\lambda_{1}\right)$ are all positive and significantly different from zero, while the coefficients on productivity a generation ago $\left(\lambda_{2}\right)$ are all negative and significantly different from zero. Also, $\lambda_{1}$ and $\lambda_{2}$ are of similar magnitude in absolute value, while the constant $\left(\lambda_{0}\right)$ is likely to be zero. 


\section{The model}

In this section, we lay out a model of the response of fertility to period by period stochastic movements in productivity. To do this, we use a model of fertility based on that developed in Becker and Barro (1988) and Barro and Becker (1989) (Barro-Becker henceforth). The simplification that we make is to assume that there is no physical (or human) capital in the model. Thus, the flow of income is solely due to wage income. ${ }^{7}$ On the other hand, we add a stochastic component as well as an explicit age-structure to the basic Barro-Becker model.

\subsection{Model setup}

A period is 20 years. Every person lives for four periods, one as a child and $T=3$ periods as an adult. There is an initial age distribution of the population given by $\left(N_{0}^{3}, N_{0}^{2}, N_{0}^{1}\right)$ where $N_{0}^{3}$ is the number of initial old (i.e., their age in period $t=0$ is $a=3$ ). We will normalize by assuming that $N_{0}^{3}=1$.

Children (age $a=0$ ) do nothing. At age $a=1$, young workers consume, have children and supply one unit of labor (net of time spent to raise children) to earn a wage, $w_{t}^{1}$. At age $a=2$, old workers consume and supply one unit of labor inelastically to earn a wage, $w_{t}^{2}$, but are no longer fertile. In the last period of their lives, age $a=3$, agents are retired and only consume.

Adults care about consumption, the number of children and their children's future utility. Following the original Barro-Becker formulation, we assume that the utility of a person who was born in period $t-1$ and whose first period as an adult is in period $t$ is given by:

$$
U_{t}^{1}=V_{t}^{1}+\phi \beta g\left(n_{t}\right) U_{t+1}^{1}
$$

where $U_{t}^{1}$ represents the full value of utility of an age $a=1$ adult in period $t$ looking from that point forward, $V_{t}^{1}$ is the utility this person gets from his own path of consumption, $n_{t}$ is the number of children that he has and $U_{t+1}^{1}$ is the utility that his typical child will receive.

Let $c_{s}^{a}$ be the amount of consumption for the typical person in period $s$ that is age $a$. We assume that utility from the time path of own consumption $\left(\left(c_{t}^{1}, c_{t+1}^{2}, c_{t+2}^{3}\right)\right.$ - young worker, old worker, retirement) is of the form:

$$
V_{t}^{1}=\sum_{a=1}^{3} \beta^{a-1} u\left(c_{t+a-1}^{a}\right) .
$$

We distinguish between time preference as measured by the discount factor, $\beta$ and the

\footnotetext{
${ }^{7}$ We relax this assumption in Section 5.3.
} 
degree of altruism between generations within a period, $\phi$. That is, $\phi=1$ means that a person cares as much about the utility of his children as he cares about his own (see Manuelli and Seshadri, 2009).

Similarly to equation (1), we can define the continuation utility for a person who was a young adult in period $t$ (i.e., he was born in period $t-1$ ) looking forward from the point when he reaches age $a>1$. Of particular interest is the continuation utility of an adult of age $T$ in period 0 - i.e., the initial old. These are the only agents in the model who care about all agents of all ages in all periods. Sequentially substituting $V$ and $U$ for later generations and grouping terms by period instead of generations, utility for the initial old, $U_{0}^{T}$, is given by:

$$
U_{0}^{T}=\sum_{t=0}^{\infty}(\beta \phi)^{t}\left[\sum_{a=1}^{T} \phi^{1-a}\left[\Pi_{k=0}^{t-1-a} g\left(n_{k}\right)\right] u\left(c_{t}^{a}\right)\right]
$$

Assuming $g(n)=n^{\eta}$, simplification occurs in equation (3) because $g\left(n_{t}\right) g\left(n_{t+1}\right)=g\left(n_{t} n_{t+1}\right)$. To see this, let $N_{t}^{a}$ be the number of descendants of the initial age $T$ agent, that are of age $a$ in period $t$. Then the laws of motion for population are given by:

$$
\begin{aligned}
& N_{t}^{1}=n_{t-1} N_{t-1}^{1} \text { is the number of births in period } t-1 ; \\
& N_{t}^{a}=N_{t-1}^{a-1} \text { for } a=2, \ldots, T \\
& N_{t}^{a}=0 \text { for } a>T \\
& N_{0}^{T}=1 .
\end{aligned}
$$

Using the functional form assumption for $g$ and the laws of motion for population, $U_{0}^{T}$ can be written as:

$$
U_{0}^{T}=\sum_{t=0}^{\infty}(\beta \phi)^{t}\left[\sum_{a=1}^{T} \phi^{1-a} g\left(N_{t}^{a}\right) u\left(c_{t}^{a}\right)\right]
$$

Hence, as is standard in dynastic models à la Barro-Becker, the utility of the initial old can be written in terms of the number of descendants of age $a$ in period $t, N_{t}^{a}$. Assuming $u(c)=\frac{c^{1-\sigma}}{1-\sigma}$, following Jones and Schoonbroodt (2010), there are two sets of parameter restrictions that satisfy the natural monotonicity and concavity restrictions of $U_{0}^{T}$ :

AI. $\quad 0<1-\sigma \leq \eta<1$;

AII. $\quad 0>1-\sigma \geq \eta .^{8}$

\footnotetext{
${ }^{8}$ The knife-edge case where $\sigma \rightarrow 1$ and $\eta=\delta(1-\sigma)$ can also be analyzed. See Jones and Schoonbroodt
} 
Under AI., $g$ is increasing and utility is positive, while under AII. $g$ is decreasing but utility is negative, so that, in both cases, ancestor's utility is increasing in the number of descendants. Also, under AI. the desire to smooth consumption over time and across generations is low, while under AII., it is high. These distinctions are relevant for the results below.

We assume that the cost of children born in period $t$ is in terms of period $t$ consumption but allow this cost to depend on the wage of young workers $-\theta_{t}\left(w_{t}^{1}\right)$. Thus, this allows for the two most common ways of modeling child costs: goods costs $-\theta_{t}\left(w_{t}^{1}\right)=\theta_{t}$ - and time costs $-\theta_{t}\left(w_{t}^{1}\right)=b w_{t}^{1}$. Thus, feasibility for the dynasty in period $t$ is given by:

$$
\sum_{a=1}^{3} N_{t}^{a} c_{t}^{a}+\theta_{t}\left(w_{t}^{1}\right) N_{t}^{b} \leq \sum_{a=1}^{2} w_{t}^{a} N_{t}^{a} \equiv W_{t}
$$

where $N_{t}^{b}=n_{t} N_{t}^{1}=N_{t+1}^{1}$ is the total number of births in period $t$. If the costs are in terms of time, $\theta_{t}=b w_{t}^{1}$, there is an additional constraint, namely that $0 \leq b N_{t}^{b} \leq N_{t}^{1}$.

We assume that wages grow at a constant rate, $\gamma$, on average. Moreover, there is an aggregate shock so that the entire age-specific wage profile shifts up and down by $s_{t}$ in period $t$. Thus, in period $t$, wages are given by:

$$
\left(w_{t}^{1}, w_{t}^{2}\right)=\left(\gamma^{t} s_{t} w^{1}, \gamma^{t} s_{t} w^{2}\right)
$$

We assume that $s_{t}$ is a first-order Markov Process.

To ensure the existence of a balanced growth path, we also assume that the costs of children grow at rate $\gamma$. That is, we assume that, $\theta\left(w_{t}^{1}\right)=\gamma^{t} \theta$ in the goods cost case and $\theta\left(w_{t}^{1}\right)=\gamma^{t} b w^{1}$ in the time cost case.

To complete the specification of the model we need to make a decision about which agents get to choose what and when. There are many different ways to do this. A useful benchmark is a Planner's problem approach. Accordingly we analyze the problem that maximizes the overall utility of the initial old. This has two advantages as a benchmark. First, this is the only group that cares, either directly or indirectly about all agents in the model. Second, it has the feature that the resulting allocation can also be supported dynamically as the equilibrium of a game in which in each period, the oldest individuals make choices for all variables for all of their descendants.

Given this, the Planner's Problem, $P\left(\gamma, \beta ;\left\{N_{0}^{a}\right\}, s_{0}\right)$, is to choose $\left\{\left\{c_{t}^{a}\left(s^{t}\right)\right\}_{a=1}^{3}, N_{t+1}^{1}\left(s^{t}\right)\right\}_{t=0}^{\infty}$ to maximize utility in (5) subject to feasibility in (6) and laws of motion of population in (4) where $s^{t}=\left(s_{0}, s_{1}, \ldots, s_{t}\right)$ is the history of shocks up to and including period $t$.

(2010) or Schoonbroodt and Tertilt (2010) for details. 
As is usually true in models with exogenous, trend growth, solutions can be obtained by solving a related model with no growth and a different discount factor. Thus, the solution to $P\left(\gamma, \beta ;\left\{N_{0}^{a}\right\}, s_{0}\right)$ can be obtained directly from the solution to $P\left(1, \hat{\beta} ;\left\{N_{0}^{a}\right\}\right.$, s $\left.s_{0}\right)$ - i.e., $\gamma=1$ (no growth) and the discount factor, $\hat{\beta}$, depends on $\gamma, \beta, \sigma$, and $\eta$. Because of this result, we abstract from trend growth through most of the remainder of the paper. In those cases where the solution to the model depends on the discount factor, we will use this result to calibrate to the appropriate discount factor in the detrended model.

Let us introduce one additional piece of notation. Let $n_{t}^{b} \equiv \frac{N_{t}^{b}}{0.5 N_{t}^{1}}$ be the number of births per woman. This is the model quantity that we will identify with the Cohort Total Fertility Rate (CTFR) in the data, while TFR will be a weighted average over several cohort's fertility.

\subsection{Consumption across the age distribution}

First, we analyze how consumption within a given period, $t$, is distributed across the different ages of agents alive at the time. The relevant term in a typical period, $t$, is:

$$
\sum_{a=1}^{3} \phi^{1-a} g\left(N_{t}^{a}\right) u\left(c_{t}^{a}\right)=\sum_{a=1}^{3} \phi^{1-a} g\left(N_{t}^{a}\right) u\left(\frac{N_{t}^{a} c_{t}^{a}}{N_{t}^{a}}\right)=\sum_{a=1}^{3} \phi^{1-a} g\left(N_{t}^{a}\right) u\left(\frac{C_{t}^{a}}{N_{t}^{a}}\right)
$$

where $C_{t}^{a}=N_{t}^{a} c_{t}^{a}$ is the total consumption of the age $a$ cohort in period $t$.

Given any level of aggregate consumption in a period, $C_{t}$, the planner will choose a distribution across ages to maximize the above subject to $\sum_{a=1}^{3} C_{t}^{a}=C_{t}$. It follows that this is done by equating the marginal utility of a unit of aggregate consumption across the different ages.

To gain more intuition, consider the Planner's objective within a period:

$$
\sum_{a=1}^{3} \phi^{1-a}\left(N_{t}^{a}\right)^{\eta+\sigma-1} \frac{\left(C_{t}^{a}\right)^{1-\sigma}}{1-\sigma}
$$

As can be seen, the marginal utility of $C_{t}^{a}$ is affected by three things. First, is $g$ increasing (AI) or decreasing (AII) in $N$ ? Second, is $N$ growing over time? Third, what is $\phi$ ?

For example, suppose $\phi=1$. In this case, the age $a$ term is $g\left(N_{t}^{a}\right) u\left(\frac{C_{t}^{a}}{N_{t}^{a}}\right)$. If population is growing (the case typically of empirical interest), then $N_{t}^{a}$ is decreasing in $a$ - there are less people in older generations. Thus, if $g$ is increasing (decreasing) in $N, g\left(N_{t}^{a}\right)$ is decreasing (increasing) in $a$. Thus, other things equal, the marginal value of an increase in per capita consumption within a period is decreasing (increasing) in age. On the other hand, in this case a given level of aggregate consumption in a cohort is split across fewer people in older groups increasing per capita consumption. This leads to a lower value of $u^{\prime}$. 
Thus if $g$ is increasing in $N$, whether the Planner will want consumption to be increasing or decreasing in age within a particular period will depend on which of these two effects is larger. If $g$ is decreasing in $N$, then if population is growing, per capita consumption is increasing in $a$ for sure. For example, specializing further to the case where $\eta=1-\sigma$ (allowed under both configurations), and $\phi=1$, period $t$ utility becomes:

$$
\sum_{a=1}^{3} \frac{C_{t}^{a 1-\sigma}}{1-\sigma}
$$

Thus, aggregate consumption of all age groups within a period will be equalized, $C^{a}=C^{a^{\prime}}$ for all $a, a^{\prime}$, and hence, larger age groups (younger cohorts if $N$ is increasing) will have smaller per capita consumption $-c_{t}^{a}<c_{t}^{a^{\prime}}$ for $a<a^{\prime}$.

\subsection{Procyclical fertility and endogenous oscillations}

In this section we study the properties of the solution to the Planner's Problem outlined above. In particular, we characterize how the policy functions from this problem depend on both the current shock and the initial state.

To gain some intuition about the working of the model, notice that if $\eta=1-\sigma$, then $N$ does not enter the period utility function except in aggregate consumption, and hence, if people are productive for only one period $\left(w^{a}=0, a \neq 1\right), N$ plays exactly the same role in this model as $k$ does in a stochastic $A k$ model. ${ }^{9}$ Similar to $A k$ models, without exogenous growth (i.e., $\gamma=1$ ), aggregate consumption, $C$, grows at the same rate as $N$. However, in the absence of shocks, per capita consumption is constant. There is one important twist to the $A k$-analogy. This is that, at least in the case where child-rearing is modeled as a time cost, the cost of the investment good is also stochastic. In that case, since $\theta_{t}=b w_{t}^{1}$, periods when productivity is high are also periods when children - the analog of the investment good in the $A k$ model - are expensive. Other than that, the analogy is very close.

We now derive comparative statics of current fertility with respect to productivity shocks and last period's fertility. To do this, we first simplify the problem to one with only one state variable. We then take first-order conditions and analyze comparative statics across steady states/balanced growth paths therein.

Denote by $V\left(N^{1}, N^{2}, N^{3} ; s\right)$ the maximized value obtained in the problem $P\left(1, \widehat{\beta} ;\left\{N_{0}^{a}\right\}, s_{0}\right)$ when the initial conditions are $\left(N_{0}^{1}, N_{0}^{2}, N_{0}^{3}\right)=\left(N^{1}, N^{2}, N^{3}\right)$ and $s_{0}=s$. Because of our assumptions on the functional forms for the utility function, it is straightforward to show that the value function is homogeneous of degree $\eta$ in $\left(N^{1}, N^{2}, N^{3}\right)$, i.e., $V\left(\lambda N^{1}, \lambda N^{2}, \lambda N^{3} ; s\right)=$ $\lambda^{\eta} V\left(N^{1}, N^{2}, N^{3} ; s\right)$. The problem $P\left(1, \widehat{\beta} ;\left\{N_{0}^{a}\right\}, s_{0}\right)$ is therefore a standard, stationary dy-

\footnotetext{
${ }^{9}$ See Jones and Manuelli (1990) and Rebelo (1991), seminal papers on this model.
} 
namic program as long as $s$ is first-order Markov. Because of this result, we can characterize the solution through Bellman's Equation.

Under the additional assumptions that $\eta=1-\sigma$, and $\phi=1$, as discussed in Section 3.2, $C^{a}=C^{a \prime}$ and $V$ satisfies:

$$
V\left(N^{1}, N^{2}, N^{3} ; s\right) \equiv \max _{N^{a^{\prime}}, C, N^{b}}\left[T \frac{C^{1-\sigma}}{1-\sigma}+\beta \phi E\left[V\left(N^{1 \prime}, N^{2 \prime}, N^{3 \prime} ; s^{\prime}\right) \mid s\right]\right]
$$

subject to:

$$
\begin{aligned}
& T C+\theta N^{b} \leq s \sum_{a=1}^{2} w^{a} N^{a} \\
& N^{a \prime}=N^{a-1}, \text { for } a=2,3 ; \\
& N^{1 \prime}=N^{b} .
\end{aligned}
$$

As can be seen from this, since $w^{3}=0$ by assumption, we have that $V\left(N^{1}, N^{2}, N^{3} ; s\right)=$ $V\left(N^{1}, N^{2}, N^{3 *} ; s\right)$ for any $N^{3}, N^{3 *}$. Assuming further that shocks are i.i.d. and using the homogeneity property of $V$, the Bellman Equation in (7) is equivalent to one where fertility per young person, $n^{\prime}=N^{b} / N^{1}$, is the choice variable and last period's fertility per person, the current stock of young to old workers $n=\frac{N^{1}}{N^{2}}$ is the state variable. That is, let $\widehat{V}(n ; s)=$ $V\left(N^{1} / N^{2}, 1 ; s\right) / T$, then $(7)$ becomes:

$$
\widehat{V}(n ; s) \equiv \max _{n^{\prime}}\left[\left(\frac{s\left[w^{1} n+w^{2}\right]-\theta(s) n^{\prime} n}{T}\right)^{1-\sigma} /(1-\sigma)+\beta n^{1-\sigma} E\left[\widehat{V}\left(n^{\prime} ; s^{\prime}\right)\right]\right] .
$$

Taking the first-order condition with respect to $n^{\prime}$ and rearranging gives:

$$
L H S\left(n^{\prime}\right) \equiv \frac{\theta(s)}{T E \hat{V}_{1}\left(n^{\prime}, s^{\prime}\right)}=\left(\frac{s\left[w^{1}+\frac{w^{2}}{n}\right]-\theta(s) n^{\prime}}{T}\right)^{\sigma} \beta \equiv R H S\left(n^{\prime}\right) .
$$

$L H S\left(n^{\prime}\right)$ is increasing in $n^{\prime}$, with $\operatorname{LHS}(0)=0$ if $E \hat{V}_{1}(0, s)=\infty$. Also, $R H S\left(n^{\prime}\right)$ is decreasing in $n^{\prime}$ with a positive intercept at $n^{\prime}=0$. Thus, there is a unique solution.

To see the behavior of $n^{\prime}$ as a function of the shock, we consider the two extreme cases, $\theta(s)=\theta$, a goods cost, and a time cost, $\theta(s)=b s w^{1}$. In the first case, $\theta(s)=\theta, R H S$ shifts up when $s$ goes up while $L H S$ is unchanged. Thus, $n^{\prime}$ is increasing in $s$ - fertility is procyclical. This is a pure income effect which is larger, the larger $\sigma$, i.e. the desire to smooth consumption. Also, it follows that $n^{\prime}$ is linear in $s$. On the other hand, when $\theta(s)=b s w^{1}$, both LHS and RHS shift up when $s$ increases. The effect on $R H S$ is still the pure income effect, which tends to increase fertility and is increasing in $\sigma, s^{\sigma}$. The effect on $L H S$ is the substitution effect because when $s$ is high, fertility is temporarily more expensive which tends to decrease fertility. This effect is linear in $s$. If $\sigma>1$, the income effect dominates, i.e. $R H S$ shifts up by more than $L H S$. Thus, again $n^{\prime}$ is increasing in $s$ - fertility is procyclical. 
If, $\sigma<1$ the substitution effect dominates - fertility is countercyclical.

To see how current fertility (per young adult), $n^{\prime}$, depends on past fertility, $n$, notice that $R H S$ shifts down when the current state, $n$, increases while $L H S$ is independent of $n$. Thus $n^{\prime}$ decreases when $n$ increases, generating cycles. This crucially depends on $w^{2}>0$. If there is only one period of working life (as in standard Barro-Becker models), this effect is zero. ${ }^{10}$

We summarize these results in the following proposition:

Proposition 1. Current fertility, $n^{\prime}(n, s)$, is

1. a. procyclical if $\theta\left(w^{1}\right)=\theta$, or if $\theta\left(w^{1}\right)=b s w^{1}$ and $\sigma>1$;

b. countercyclical if $\theta\left(w^{1}\right)=b s w^{1}$ and $\sigma<1$;

2. a. independent of last period's fertility, $n$, if $w^{2}=0$;

b. decreasing in last period's fertility, $n$, if $w^{2}>0$.

Thus, if $w^{2}>0$ the model generates endogenous cycles, triggered by productivity shocks.

The intuition for why fertility is procyclical in this model is similar to that in many growth models. Here, fertility plays the role of an investment good and the usual consumption smoothing logic implies that when the shock is high, investment should be high so as to offset the effects of future shocks on consumption. This argument is direct when the cost of children is a goods cost. It is tempered when the cost is a time cost by a second effect. This is that the cost of the investment good is also higher than average when the shock is high. Thus, whether or not it is a good idea to invest in those periods depends on how strong the desire is to smooth consumption. When this force is strong $-\sigma$ is large - the consumption smoothing effect is large relative to the cost effect and fertility is procyclical. Thus, the more important the time cost in raising children, the more procyclical is the cost of children itself. That is, whenever productivity is high, the cost of children is also high and vice versa. This dampens the procyclicality of fertility and, indeed, when the desire to smooth consumption is very low, fertility actually is countercyclical.

Some intuition for the fertility cycles in point 2 of the proposition can also be obtained by analogy with growth models. Here, what we find is a source of endogenous cycles. The relevant analogy from capital theory here is to consider a model in which depreciation is not constant. Here, we have an extreme version. Capital (i.e., people) that is built in period $t-1$ has full productive capacity in period $t$ and period $t+1$ - there is no depreciation between periods $t$ and $t+1$ - but has zero productive capacity in period $t+2$. Thus, age-specific depreciation rates here would be $\delta_{1}=0$ and $\delta_{2}=1$ - no depreciation after one period,

\footnotetext{
${ }^{10}$ Note that since the number of births per woman (CTFR) is $n^{b}=n / 0.5$, all these comparative statics go through without change.
} 
full depreciation after two. In a situation like this, when $n=N^{1} / N^{2}$ is higher than usual, the planner expects next periods depreciation rate to be lower than usual (because $N^{2}$ is relatively low). Because of this, to smooth consumption, current investment $-n^{\prime}=N^{b} / N^{1}$ - will be relatively low. Thus, $n^{\prime}$ is low when $n$ is high. When there is only one period of working life, the depreciation rate is always 100 percent and hence this effect is not present. Because of this, fertility is independent of last period's fertility. The example with one period working life, $w_{t}^{2}=0$, is interesting because it corresponds most closely to that of the original Barro-Becker model while the model with more than one period productive life is more realistic. ${ }^{11}$

Thus, according to our theory, while the baby bust in the 1930s may be explained by the Great Depression, the baby boom in the 1950s is first and foremost a response to low fertility in the past.

\section{Quantitative results}

In this section, we use the facts about the time paths of productivity and fertility in the U.S. over the 20th century laid out in Section 2 to perform quantitative experiments on the model. To do this, we calibrate parameters to selected moments of our data. We then use this model to explore two kinds of questions. First, what does the calibrated model say about the size of responses to shocks to productivity - e.g., what is the elasticity of fertility with respect to a productivity shock? In keeping with the theoretical results of the previous section we study both the current response to a shock and also the lagged response one generation later due to the misalignment of the age structure of the workforce. Second, based on the estimated policy functions from the calibrated model we study the predicted response to a productivity shock like those seen in US history - e.g., the Great Depression.

We find that the answers to these quantitative questions also depends on the nature of the costs of children. Because of this, we give results for two alternative specifications. These are: (1) all costs are time costs $\left(\theta(s)=b w^{1} s\right)$; (2) all costs of raising children are goods costs $(\theta(s)=\theta)$. As noted above, these two specifications are qualitatively different in that with a time cost, the costs of children are higher in productivity booms than in busts. Reality probably lies somewhere inbetween these two extreme cases. ${ }^{12}$

We find that the quantitative responses in the model are economically significant in all

\footnotetext{
${ }^{11}$ In Section 5.4 we add a third period of working life to show that results, though qualitatively more complicated, are very similar quantitatively.

${ }^{12}$ Indeed, the time cost may have become more relevant over time as women entered the labor force. Since women tend to be the parent taking care of children, the relevant opportunity cost is only procyclical if the latter are actually working whenever they are not busy raising children.
} 
cases. For example, the elasticity of fertility to a contemporaneous productivity shocks lies between 1 and 1.7, ${ }^{13}$ while the elasticity one period later lies between 0.94 and 1.5. Standard recessions will have rather modest effects on fertility, however. Large recessions, such as the Great Depression, on the other hand, have important and long lasting effects.

We therefore turn to the historical record of the United States and study the predicted response of fertility to the productivity booms and busts over the 20th century. To do this, we must first construct a series of shocks to feed into the model. It is not obvious how to do this realistically. On the one hand, in the model, it is assumed that the shock for the current period is realized at the beginning of the period. Effectively, this means that individuals know, at the beginning of the period, what the sequence of annual shocks will be over the next 20 years. Even with highly correlated shocks at annual frequency, this assumption seems extreme at best. Another alternative is to decrease the length of a period. This necessarily increases the size of the state space. For example, even decreasing the period length to 10 years and maintaining the i.i.d. assumption increases the size of the state space from 2 dimensional to $5 .{ }^{14}$ Relaxing the $i . i . d$. assumption which might be required for 10as opposed to 20-year periods, adds another state variable. In addition, one would have to address timing of births (between age 20-30 versus 30-40) more seriously. This is not an easy problem (see Caucutt et al. (2002), Doepke et al. (2007) and Sommer (2010) for examples). Thus, there are technical difficulties with following the strategy of decreasing the period length.

Because of this, we present results for several alternative methods for constructing the relevant series of productivity shocks for TFP and LP. First, since the data shows that over the period 1940 to 1980 at least 60 percent of all births are to women age 20 to $30,{ }^{15}$ we assume that women have all their children between age 21 and 30. As our baseline experiment, we therefore assume that the relevant productivity shock for them is the average one in the data for that 10 year period. We conduct sensitivity analysis on this specification in Section 5.1. We also have to choose which productivity measure to use, total factor productivity (TFP) or labor productivity (LP). We use TFP in our baseline case and discuss LP in Section 5.2.

In our baseline experiment, a shock to productivity (or labor income) the size of the Great Depression gives rise to a contemporary baby bust that accounts for 64 to 103 percent of the

\footnotetext{
${ }^{13}$ As will be seen below, the model response to a shock is smaller when the cost is in terms of time than when it is in terms of goods. Thus, 'between 1 and 1.7 ' corresponds to 1 with a time cost and 1.7 with a goods cost.

${ }^{14}$ The state space is three-dimensional in our problem: $N^{1}, N^{2}$ and $s$. Using the homogeneity results, this can be reduced to two state variables, $N=N^{1} / N^{2}$ and $s$. With 10-year periods (and age-groups) the problem becomes six-dimensional: $N_{b}^{2}, N^{1,1}, N^{1,2}, N^{2,1}, N^{2,2}$ and $s$, which using the same methods can be reduced to a five-dimensional problem.

${ }^{15}$ See Vital Statistics of the United States, Table 1-7.
} 
reduction in CTFR and 39 to 63 percent of the reduction in TFR seen in the data. Further, the model prediction of the lagged response to such a shock is a baby boom. Combined with the productivity boom in the 1950s and 1960s, the predicted size of the baby boom lies between 84 and 150 percent of the actual size of the baby boom observed in the CTFR data and 53 to 92 percent of the one observed in the TFR data.

\subsection{Parameterization}

Preference Parameters: Throughout, we assume that $\eta=1-\sigma$ and set $\sigma=3$ following Jones and Schoonbroodt (2010) among others. ${ }^{16}$ The discount factor is set to $\beta=0.96^{20}$ to match an annual interest rate of about 4 percent.

Wage and Productivity Parameters: From the model, wages are given by $w_{t}^{a}=s_{t} \gamma^{t} w^{a}$, where $w^{a}$ is the base wage (in period 0) for workers of age $a=1,2, \gamma$ is the trend productivity growth rate for a 20-year period and $s_{t}$ is the productivity shock which we assume to be i.i.d. over time. ${ }^{17}$ Further, for computational reasons, it is convenient to assume a functional form for the distribution of productivity shocks, $s_{t}$. We assume that $\ln \hat{s}_{t} \sim N\left(0, \sigma_{s}^{2}\right)$ where $\hat{s}_{t}=s_{t} e^{\sigma_{s}^{2} / 2}$ so $E\left(s_{t}\right)=1$. Thus, the parameter values to be determined are $w^{1}, w^{2}, \gamma$ and $\sigma_{s}$.

We normalize $w^{1}=1$ and choose $w^{2}=1.25$. This is in line with life-cycle earnings profiles from Hansen (1993) and Huggett (1996). The growth rate of productivity, $\gamma$, and the standard deviation of productivity shocks, $\sigma_{s}$, are calculated from the TFP series plotted in Figure 1. First, we compute the linear trend in productivity by running the following ordinary least-squares regression on annual data:

$$
\ln T F P_{t}=\alpha_{0}+\alpha_{1} t+\epsilon_{t}
$$

We find that $\alpha_{1}=0.0159$ and therefore set $\gamma=\left(e^{\alpha_{1}}\right)^{20}=1.0161^{20}$. That is, productivity grows at an average of 1.61 percent per year over the 20 th century. ${ }^{18}$

To pin down the value of $\sigma_{s}$ several steps are required. First, in our baseline experiment, we use the 10 most fertile years of each cohort within a dynasty, namely age 20 to 30 , to determine the productivity shock this cohort's fertility choice is affected by. Thus, the shock we are interested in is $\ln \hat{s}_{t}=\ln \left(\sum_{t=1}^{10} e^{\epsilon_{t}}\right)-\mu$ where $\mu=E\left(\ln \left(\sum_{t=1}^{10} e^{\epsilon_{t}}\right)\right)$. To approximate

\footnotetext{
${ }^{16}$ e.g., Mateos-Planas (2002) and Scholz and Seshadri (2009) also use a value of $\sigma=3$.

${ }^{17}$ This is a reasonable approximation for long movements in labor productivity across generations, which within a dynasty are 20 years apart.

${ }^{18} \mathrm{An}$ alternative detrending method would be to use a Hodrick-Prescott filter, instead. However, it is not clear what value to use for the smoothing parameter since we are interested in long fluctuations, rather than quarter-to-quarter or annual deviations from trend. In any case, for low enough smoothing parameter resulting productivity shocks would typically be smaller. Assuming that the growth rate of productivity is constant in the model but using HP productivity shocks would result in smaller fertility responses in the experiments at the end of this and the next section.
} 
its standard deviation, $\sigma_{s}$, we assume that $\epsilon_{t}$ follows an AR1 process and estimate

$$
\epsilon_{t}=\rho_{0}+\rho_{1} \epsilon_{t-1}+\nu_{t}
$$

where $\nu_{t} \sim N\left(0, \sigma_{\nu}\right)$, simulate a long series of $\left\{\epsilon_{t}\right\}$, compute a series $\left\{\ln s_{t}\right\}$ and calculate its standard deviation to get $\sigma_{s}=0.07$. Of course, the series, $\ln s_{t}$, so constructed is not exactly normally distributed. However, for all simulations, the Kolmogorov-Smirnov test produces a $p$-value of about 0.4 . This means that, at any reasonable significance level, the test would accept the null hypothesis that the distribution of $\ln s_{t}$ is normal and hence this should provide a good approximation.

Costs of Children: Given preference and productivity parameters, we then calibrate child costs, $\theta(\cdot)$, to match an annual population growth rate of 0.645 percent per year (see Haines, 1994, Table 1). In the model, population growth corresponds to $\frac{N_{b}+N^{1}+N^{2}}{N^{1}+N^{2}+N^{3}}$. In a steady state with no uncertainty, this is given by the level of fertility choice (per person), $n^{s s}$, satisfying $n^{\prime}\left(n^{s s}, 1\right)=n^{s s}$. Thus, the target is $n^{s s}=1.00645^{20}$. This corresponds to a steady state CTFR level of $n^{s s} / 0.5=2.27$ children per woman. In the goods cost case, we find $\theta=0.1932$, while with time costs we find $b=0.1927$. Since the wage for young workers is normalized to 1 , these costs imply that it takes about 20 percent of a young worker's income or time to produce a child. This means that a two person household can at most have ten children.

Summary: These parameters are summarized in Table $2 .{ }^{19}$

Table 2: Parameter Values, Baseline

\begin{tabular}{l|c|c|c|c|c|c|c|c}
\hline \hline Parameter & $\sigma$ & $\beta$ & $w^{1}$ & $w^{2}$ & $\gamma$ & $\sigma_{s}$ & $\begin{array}{c}\theta \\
\text { (goods cost) }\end{array}$ & $\begin{array}{c}b \\
\text { (time cost) }\end{array}$ \\
\hline Value & 3.00 & $0.96^{20}$ & 1.00 & 1.25 & $1.0161^{20}$ & 0.07 & 0.1932 & 0.1927 \\
\hline \hline
\end{tabular}

\subsection{Model impulse responses}

Given the parameter values from the previous section we calculate the decision rules from the model. These can then be used to estimate the model responses to different size productivity shocks. The results are summarized in Table 3. The rows of the table correspond to the two alternative types of cost structures for children, goods and time. The first two columns report

\footnotetext{
${ }^{19}$ We provide sensitivity to the parameter values in the Appendix, Table A.9.
} 
the elasticities (at the steady state) of (a) current and (b) lagged fertility to productivity shocks. The next two columns give the (c) contemporaneous and (d) lagged change in fertility levels that the model predicts will result from a one percent increase in productivity. Column (e) recalls the steady state level of completed fertility (CTFR).

Table 3: Impulse Response (in percent and levels), Baseline

\begin{tabular}{l|c|c|c|c|c}
\hline \hline \multirow{2}{*}{ Cost } & \multicolumn{2}{|c|}{$\%$ Deviations } & \multicolumn{3}{|c}{ CTFR Levels } \\
\cline { 2 - 6 } Type & $\begin{array}{c}\text { Initial } \\
\text { (a) }\end{array}$ & $\begin{array}{c}\text { Lagged } \\
(\mathrm{b})\end{array}$ & $\begin{array}{c}\text { Initial } \\
(\mathrm{c})\end{array}$ & $\begin{array}{c}\text { Lagged } \\
(\mathrm{d})\end{array}$ & $\begin{array}{c}\text { Steady St. } \\
(\mathrm{e})\end{array}$ \\
\hline Goods & 1.741 & -1.561 & 2.314 & 2.239 & 2.274 \\
Time & 1.039 & -0.940 & 2.298 & 2.253 & 2.274 \\
\hline \hline
\end{tabular}

As can be seen from this table, in the goods cost case the fertility response to a 1-percent productivity shock generates a 1.74 percent contemporaneous increase in fertility (column (a)) with a lagged decrease of 1.56 percent one period later (column (b)). In the time cost case, the corresponding percentage changes are a 1.04 percent contemporaneous increase and a 0.94 decrease one period later.

These magnitudes can be compared to the regression results shown in Table 1. In particular, column (a) is to be compared with $\lambda_{1}$ and column (b) with $\lambda_{2}$. Thus, if the model fit the data perfectly we should see 0.83 in column (a), and -0.84 in column (b). Although the model quantities are higher, they are remarkably similar in the time cost case.

Comparing the two cases, the initial effect is 70 percent larger in the goods cost case than it is in the time cost case. The reason for this difference is that when child costs are primarily in terms of time there are two offsetting effects. First, when times are good there is a natural tendency to save for the future to equalize marginal utilities. Here, the only way to do this is by increasing family size. On the other hand, since the cost of raising children is positively related to the wage, when times are good, children are relatively more expensive - a force in the opposite direction. When the costs of children are in terms of goods, this second effect is not at work and hence, the overall effect is larger in this case. As can be seen in the table, as the theory predicts, the first effect dominates if the intertemporal elasticity of substitution is low enough $(\sigma>1$, see Proposition 1).

Further, since in both cases, the ratio of the initial response to the lagged response is about -90 percent, the half-life (in absolute value) of the effect is 7 periods (or generations) 
in both cases. In particular, the effect 7 periods later is a decrease in fertility of 0.8 percent in the goods cost case and 0.5 percent in the time cost case (i.e., half of the initial responses).

To get a sense about the size of these effects note that a one-percent decrease in productivity for a 10-year period roughly corresponds to a recession where GDP is 5 percent below trend for two years. This would decrease fertility by about 0.02 to 0.04 children per woman with a subsequent baby boom of similar size. Thus, the quantitative effects on (completed) fertility of a normal sized recession would be quite modest. As we shall see below, the model predicts that a recession the size of the Great Depression gives a much larger response.

\subsection{A historical episode: the U.S. Great Depression}

In this section we use the historical record of the actual series of productivity shocks in the U.S. to study the predicted response of fertility to the productivity busts and booms that have occurred over the last 100 years.

We first focus on the dynasty most affected by the Great Depression, i.e., the cohort making fertility decisions in the 1930s (followed by the 1950s cohort, the 1970s cohort and the 1990s cohort).

Second, we consider other dynasties also affected by the Great Depression but less so. That is, those making fertility choices either in the late 1920s and early 1930s (i.e., between 1926 and 1935, etc.) or in the late 1930s and early 1940s (between 1936 and 1945, etc.). Finally, we consider the dynasty making fertility choices in the 1920s (between 1921 and 1930, etc). By construction, the Great Depression has no effect on the fertility choices of this last dynasty. Thus, we simplify by assuming that there is no connection or opportunity for trade between the four dynasties. Cohorts within these dynasties make overlapping fertility decisions.

Finally, the measure of fertility constructed in this way - using different shocks for different cohorts - corresponds to CTFR since it represents completed fertility for each cohort. We also construct an analog for TFR, i.e., period fertility, by averaging over the two cohorts making their fertility decisions in any five-year period. In doing this, we solve the model separately for the different dynasties and then aggregate.

\subsubsection{CTFR: Most Affected Dynasty (M.A.D.)}

First, to focus on the effects of the Great Depression, we start with the dynasty making fertility decisions in the 1910s, 1930s, 1950s, 1970s and 1990s. This dynasty is the most

affected by the Great Depression. As a benchmark, we assume that the initial state of the dynasty is at its steady state age-distribution. In other words, the dynasty has been facing average shocks $(s=1)$ for a long time so that its current age-distribution is stationary. 
For this dynasty, the relevant series of productivity shocks, $s_{t}$, is shown in Table 4 . The results are shown in Figure 4. With a goods cost, the model predicts that fertility is 19.1 percent below trend during the $1930 \mathrm{~s}$; with a time cost the prediction is 11.8 percent below trend. In the data, CTFR actually fell by 18.5 percent. Thus, the model captures a significant fraction of this movement in either case. This is primarily due to the large, negative shock of 12.4 percent during the Great Depression of the 1930s - the dynasty's young-to-old worker ratio is initially almost at its steady state value and hence effects from this are minimal.

Table 4: Productivity shocks (in percent), Baseline (M.A.D.)

\begin{tabular}{l|r|r|r|r|r}
\hline \hline Decade & $1910 \mathrm{~s}$ & $1930 \mathrm{~s}$ & $1950 \mathrm{~s}$ & $1970 \mathrm{~s}$ & $1990 \mathrm{~s}$ \\
Productivity Shock & -1.8 & -12.43 & 6.89 & 3.90 & -8.97 \\
\hline \hline
\end{tabular}

Figure 4: Percent Deviations in CTFR, Baseline (M.A.D.)

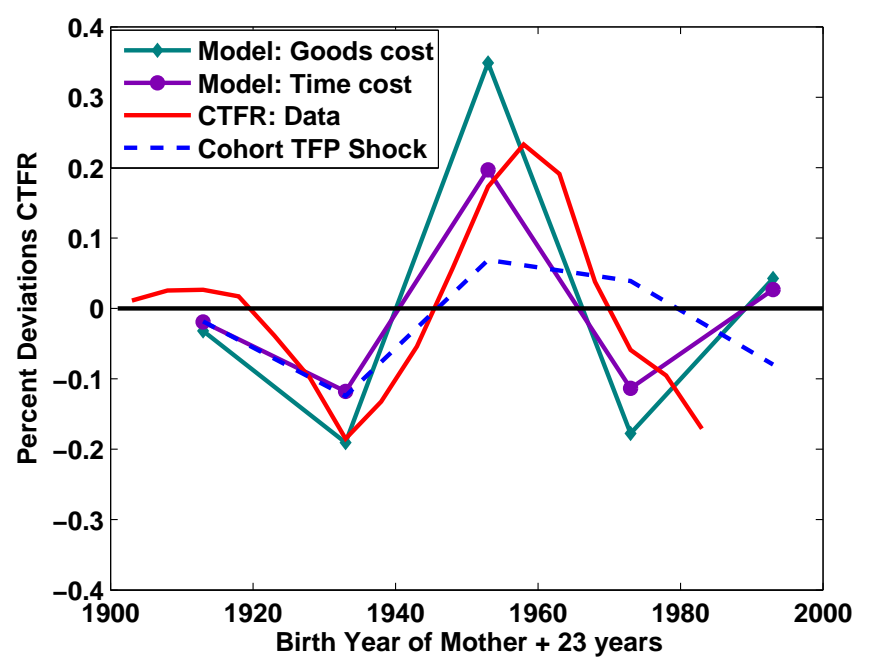

As noted above, there is also a lagged effect in the model from the Great Depression due to the misalignment of the age structure that results from low fertility during the 1930s. This implies, a baby boom for the next cohort in this dynasty which takes place in the 1950s. With a goods cost, the model prediction is an increase in fertility above trend of 34.9 percent, while with a time cost, the corresponding model prediction is 19.7 percent above trend. These model predictions result from a combination of the fertility response to the low young-to-old worker ratio due to the baby bust and the 8.4 percent productivity boom 
in the 1950s. For the purposes of comparison, the peak of the baby boom in the CTFR data is 23 percent above trend.

In the model, the Great Depression has continuing impacts on the fertility choices in this dynasty - there are continued fluctuations with a decrease of 11 to 18 percent below trend in the 1970s (due to the lagged response to the baby boom but dampened by the 3.9 percent upward fluctuation in TFP in the 1970s); this is followed by an increase of 2.7 to 4.2 percent above trend in the 1990s - again a response to the low young-to-old worker ratio dampened by the negative productivity shock of 8 percent during the 1990s.

This is an extreme version of the baby bust and boom in the model because it is constructed so that the cohort's entire fertile period falls during the Great Depression. For other cohorts or dynasties, the effects are mitigated because at least part of their fertile period is unaffected by the Great Depression. This is also true for the baby boom: the dynasty considered here is most affected by the low young-to-old worker ratio and has a large positive productivity shock in the post-war period.

\subsubsection{CTFR: All dynasties and cohorts}

Table 5 shows how we construct our four dynasties. It illustrates the state variables and shocks for each cohort. For each dynasty, we assume that the initial value of the state variable is $n=n^{s s}$, the balanced growth level of fertility. The first dynasty $\left(d_{1}\right)$ starts with women born between 1876-1880 (labeled 1880), cohort $1\left(c_{1}\right)$. They face a productivity shock, $s_{1}$, averaging over the period 1901-1910 when they are roughly age 20 to 30 . Their fertility choice is $n_{c_{1}}=n^{\prime}\left(n^{s s}, s_{1}\right)$. The second dynasty $\left(d_{2}\right)$ starts with women born five years later, between 1881-1885 (labeled 1885), cohort $2\left(c_{2}\right)$. Their first productivity shock, $s_{2}$, is obtained by averaging over 1906-15. Their fertility choice is $n_{c_{2}}=n^{\prime}\left(n^{s s}, s_{2}\right)$. The third dynasty $\left(d_{3}\right)$ starts with women born between 1886-1890 (labeled 1890), cohort $3\left(c_{3}\right)$. This is the most affected dynasty described above. The fourth dynasty $\left(d_{4}\right)$ starts with women born between 1891-1895 (labeled 1895), cohort $4\left(c_{4}\right)$. Their first productivity shock $s_{4}$, comes from averaging over the period 1916-1925. Cohort 5, born between 1896-1900 (labeled 1900) are the next generation in $d_{1}$. Their initial productivity shock $s_{5}$, comes from averaging over the period 1921-30. Thus, their fertility choice is given by $n_{c_{5}}=n^{\prime}\left(n_{c_{1}}, s_{5}\right)$. Proceeding further in this fashion leads to Cohort 9, born between 1916-1920 (labeled 1920), the third generation in dynasty 1 making fertility decisions between 1941 and 1950. The shock that this cohort faces is not affected by the Great Depression at all. We expand this series to Cohort 20, born between 1971-1975 (labeled 1975), the third generation in dynasty 1 making fertility decisions between 1996 and 2005.

The percent deviations in fertility choice in the last two column of Table 5 is what we 
Table 5: Dynasties and Cohorts, Baseline

\begin{tabular}{|c|c|c|c|c|c|c|c|c|c|c|c|}
\hline \multirow[t]{2}{*}{$\begin{array}{c}\text { Cohort } \\
\text { Label }\end{array}$} & \multirow[t]{2}{*}{$\begin{array}{c}\text { Birthyear } \\
\text { Label }\end{array}$} & \multirow[t]{2}{*}{$\begin{array}{l}\text { Fertile } \\
\text { Period }\end{array}$} & \multicolumn{2}{|c|}{$\begin{array}{l}\text { Productivity } \\
\text { Shock }\end{array}$} & \multicolumn{4}{|c|}{$\begin{array}{l}\text { State var., } n \\
\text { Dynasty }\end{array}$} & \multicolumn{3}{|c|}{$\begin{array}{c}\text { Fertility } \\
\text { Choice }\end{array}$} \\
\hline & & & Label & $\begin{array}{r}\text { Value } \\
(\%)\end{array}$ & $d_{1}$ & $d_{2}$ & $d_{3}^{*}$ & $d_{4}$ & Label & $\begin{array}{r}\text { Goods } \\
(\%)\end{array}$ & $\begin{array}{r}\text { Time } \\
(\%)\end{array}$ \\
\hline$c_{1}$ & 1880 & $1901-10$ & $s_{1}$ & -0.90 & $n^{s s}$ & $\ldots$ & $\ldots$ & $\ldots$ & $n_{c_{1}}$ & -1.57 & -0.94 \\
\hline$c_{2}$ & 1885 & $1906-15$ & $s_{2}$ & -3.85 & $\ldots$ & $n^{s s}$ & & $\ldots$ & $n_{c_{2}}$ & -6.71 & -4.06 \\
\hline$c_{3}$ & 1890 & $1911-20$ & $s_{3}$ & -1.84 & $\ldots$ & & $n^{s s}$ & $\ldots$ & $n_{c_{3}}$ & -3.20 & -1.93 \\
\hline$c_{4}$ & 1895 & $1916-25$ & $s_{4}$ & 3.02 & $\ldots$ & $\ldots$ & $\ldots$ & $n^{s s}$ & $n_{c_{4}}$ & 5.25 & 3.12 \\
\hline$c_{5}$ & 1900 & $1921-30$ & $s_{5}$ & 1.58 & $n_{c_{1}}$ & $\ldots$ & $\ldots$ & $\ldots$ & $n_{c_{5}}$ & 4.23 & 2.52 \\
\hline$c_{6}$ & 1905 & $1926-35$ & $s_{6}$ & -7.06 & $\ldots$ & $n_{c_{2}}$ & & $\ldots$ & $n_{c_{6}}$ & -6.20 & -3.79 \\
\hline$c_{7}$ & 1910 & $1931-40$ & $s_{7}$ & -12.43 & $\ldots$ & & $n_{c_{3}}$ & $\ldots$ & $n_{c_{7}}$ & -19.05 & -11.79 \\
\hline$c_{8}$ & 1915 & $1936-45$ & $s_{8}$ & -1.68 & $\ldots$ & $\ldots$ & $\ldots$ & $n_{c_{4}}$ & $n_{c_{8}}$ & -7.41 & -4.50 \\
\hline$c_{9}$ & 1920 & $1941-50$ & $s_{9}$ & 5.72 & $n_{c_{5}}$ & $\ldots$ & $\ldots$ & $\ldots$ & $n_{c_{9}}$ & 6.04 & 3.55 \\
\hline$c_{10}$ & 1925 & $1946-55$ & $s_{10}$ & 5.65 & $\ldots$ & $n_{c 6}$ & & $\ldots$ & $n_{c_{10}}$ & 16.17 & 9.50 \\
\hline$c_{11}$ & 1930 & $1951-60$ & $s_{11}$ & 6.89 & $\ldots$ & & $n_{c_{7}}$ & $\ldots$ & $n_{c_{11}}$ & 34.88 & 19.68 \\
\hline$c_{12}$ & 1935 & $1956-65$ & $s_{12}$ & 8.92 & $\ldots$ & $\cdots$ & $\ldots$ & $n_{c 8}$ & $n_{c_{12}}$ & 23.43 & 13.56 \\
\hline$c_{13}$ & 1940 & 1961-70 & $s_{13}$ & 11.14 & $n_{c_{9}}$ & $\cdots$ & $\cdots$ & $\ldots$ & $n_{c_{13}}$ & 13.61 & 7.93 \\
\hline$c_{14}$ & 1945 & $1966-75$ & $s_{14}$ & 8.91 & $\ldots$ & $n_{c_{10}}$ & & $\ldots$ & $n_{c_{14}}$ & 1.68 & 0.75 \\
\hline$c_{15}$ & 1950 & $1971-80$ & $s_{15}$ & 3.90 & $\ldots$ & & $n_{c_{11}}$ & $\ldots$ & $n_{c_{15}}$ & -17.76 & -11.34 \\
\hline$c_{16}$ & 1955 & $1976-85$ & $s_{16}$ & -1.56 & $\ldots$ & $\ldots$ & $\ldots$ & $n_{c_{12}}$ & $n_{c_{16}}$ & -19.82 & -12.48 \\
\hline$c_{17}$ & 1960 & $1981-90$ & $s_{17}$ & -4.49 & $n_{c_{13}}$ & $\cdots$ & $\ldots$ & $\ldots$ & $n_{c_{17}}$ & -18.31 & -11.31 \\
\hline$c_{18}$ & 1965 & $1986-95$ & $s_{18}$ & -5.82 & $\ldots$ & $n_{c_{14}}$ & & $\ldots$ & $n_{c_{18}}$ & -11.58 & -6.83 \\
\hline$c_{19}$ & 1970 & 1991-00 & $s_{19}$ & -7.97 & $\ldots$ & & $n_{c_{15}}$ & $\ldots$ & $n_{c_{19}}$ & 4.25 & 2.67 \\
\hline$c_{20}$ & 1975 & $1996-00$ & $s_{20}$ & -8.86 & $\ldots$ & $\ldots$ & $\ldots$ & $n_{c_{16}}$ & $n_{c_{20}}$ & 5.10 & 2.90 \\
\hline
\end{tabular}


Figure 5: Percent Deviations in CTFR, Baseline (All Cohorts)

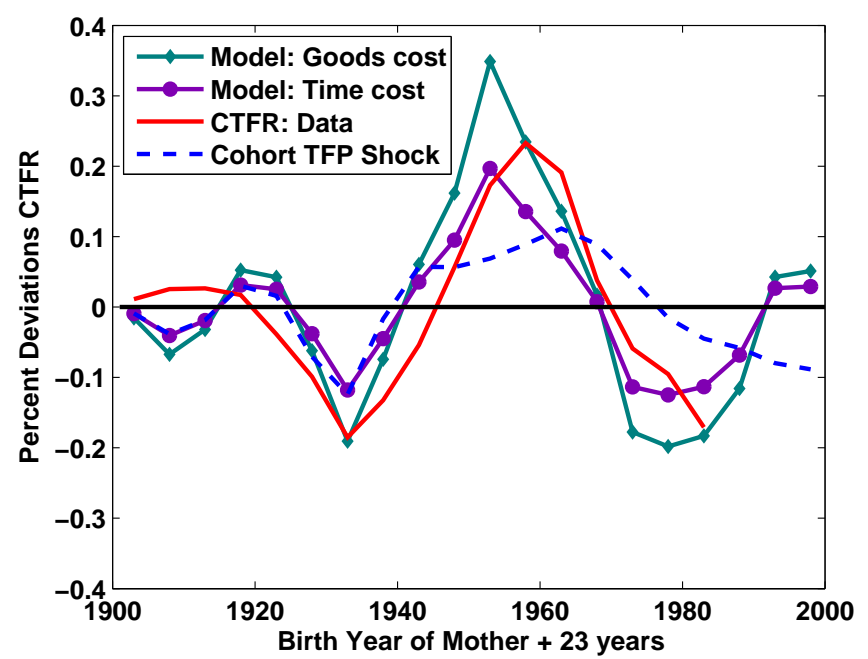

plot in Figure 5. Again, we show the results of the model for goods and time costs cases separately. Also plotted is CTFR data from Jones and Tertilt (2008). As expected, we see that dynasties other than the M.A.D. are less affected by the Great Depression. Still, there is some effect - there are smaller deviations from trend both down and up, 20 years later.

\subsubsection{TFR}

Next, we compute an analog of TFR, i.e., period fertility, by averaging over the two cohorts making their fertility decisions in any five-year period. That is, we compute TFR in any five-year period by computing the average of fertility of the two cohorts who are making half their fertility decision in that five-year period, weighted by their size (i.e., their parent's fertility choice). For example, $T F R_{1931-35}=\frac{n_{c_{6}} n_{c_{2}}+n_{c_{7}} n_{c_{3}}}{n_{c_{2}}+n_{c_{3}}}$. Note that, if all dynasties are in a steady state $C T F R=T F R=n^{s s} / 0.5$. One advantage of this fertility measure is that we have data until 2000, while for completed fertility the last cohort in Jones and Tertilt (2008) makes fertility decisions in the 1980s.

The results are shown in Figure 6. Since deviations in TFR in the data are larger than deviations in CTFR and since we are averaging over less affected cohorts, the model accounts for a smaller fraction of these deviations.

With a goods cost, the model predicts that TFR would be 12.7 percent below trend in the early and late 1930s; with a time cost, the analog is 7.8 percent. In the data, TFR is 20 percent below trend in the early 1930s and 22 percent below trend in the late 1930s. As with CTFR, this result is mainly due to the negative shock of 12.4 percent during the Great Depression but here the results are mitigated because some women don't make their entire 
Figure 6: Percent Deviations in TFR, Baseline

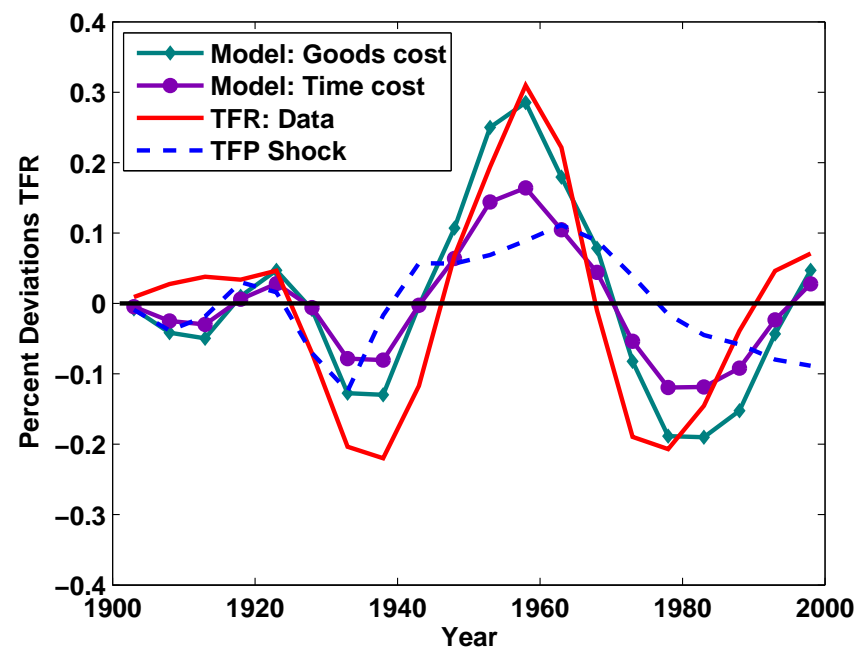

fertility decision during this period. In the data, the peak of the baby boom occurs in the late 1950 s when fertility is 31 percent above trend. With a goods cost, the model predicts TFR will be 28.5 percent above trend while with a time cost, the prediction is 16.4 percent. Again, this result is a combination of the fertility response to the low young-to-old worker ratio due to the baby bust and the productivity boom in the 1950s and early 1960s. Hence, the model accounts for 38.5 to 62.6 percent of the baby bust and for 53 to 92 percent of the baby boom in TFR.

In subsequent periods, TFR in the model keeps fluctuating - 11.9 to 18.9 percent below trend in the late 1970s (due to the prior baby boom but dampened by the 3.9 percent increase in TFP). The corresponding movements in the data on TFR is 20.7 percent below trend. The increase in fertility in the 1990s of 7.1 percent above trend in the data is also partly captured by the model which predicts a 2.8 to 4.7 percent increase.

\section{Sensitivity}

In this section, we discuss the sensitivity of our results two types of changes. The first type take the parameters in Table 2 as given but change the way productivity shocks in Section 4.3 are computed. Here, we explore (1) changes in the age range used to assign TFP shocks to different cohorts, and (2) the effects of using labor productivity (LP) instead of TFP. Given the nature of these experiments, elasticities and impulse responses remain the same but the size of shocks differs. Results are reported in Figure 7. Increasing the age range tends to decrease the effect of the Great Depression on fertility because it is diluted 
across more cohorts. Therefore, the predicted size of the baby boom is also smaller. It also affects the timing of the baby bust and boom. The results using labor productivity are very similar to the baseline, except for the cohort making fertility decisions in the 1910s who experience a productivity boom and those making fertility decisions in the 1920s who experience a significant negative shock. Due to endogenous fluctuations, these changes work themselves through the fertility fluctuations later on in the century.

The second type of change that we explore involves altering some of the basic features of the model. Here we study the robustness of our results both to including capital and having more (i.e., shorter) time periods and hence, more active generations. We find that our basic results are robust to these two qualitative changes to the model.

\subsection{Age range of productivity shocks}

One problem with the assumption that the only relevant shock for the dynasty is when their youngest cohort is age 20 to 30 is that it implicitly assumes that the shock lasts for the entire period of 20 years. In this section, we describe model results when the shock is set to the average productivity shock over the period where the cohort is age 20 to 40 .

Figure 7(a), shows cohort productivity shocks for this experiment compared to the baseline. Overall shocks are smoother and smaller because some busts and booms are smoothed out due to the longer time period. Also, Cohort $c_{5}$ making part of their fertility decisions in the 1920s faces a relatively large negative shock due to the Great Depression in the 1930s when $c_{5}$ is age 30 to 40 . Therefore, the baby bust starts earlier and is smaller than in the baseline model as can be seen in Figure 7(b). Because of the smaller baby bust in the 1930s and smaller shocks, the baby boom is also smaller and so are subsequent fluctuations.

The problem with this alternative is that it implicitly assumes that fertility is uniform between age 20 and 40 . Hence, the fertility decision of women born at the beginning of the century is heavily affected by the Great Depression in this experiment when in reality most of them had completed their fertility in the 1920s.

Since this alternative is at the opposite extreme of the baseline, the two experiments together should give us reasonable bounds on how much of the fluctuations in fertility over the 20 th century in the U.S. the model can account for. ${ }^{20}$

\subsection{Labor productivity versus total factor productivity}

Since there is no capital in our model, it is not clear wether we should use labor productivity (LP) or total factor productivity (TFP) to infer productivity shocks. The argument for using

\footnotetext{
${ }^{20}$ In Appendix A.2 we perform an experiment where TFP shocks are weighted by average age-specific fertility rates. This is an intermediate case between the baseline and the present experiment.
} 
Figure 7: Percent Deviations in TFR, Age Range and Labor Productivity

(a)

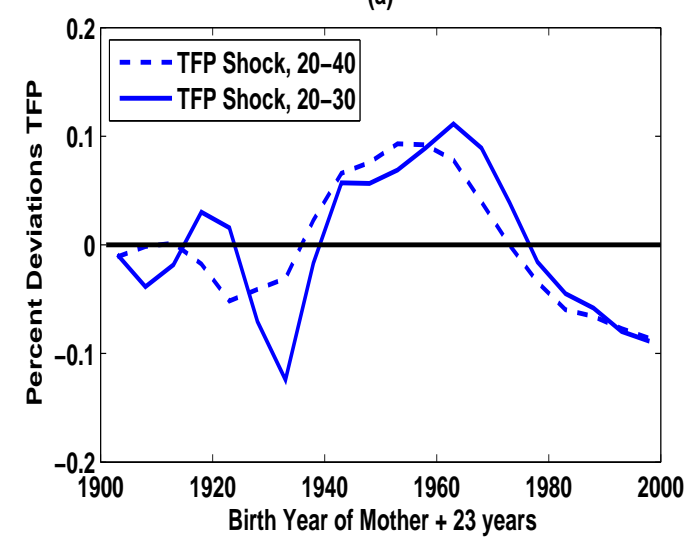

(b)

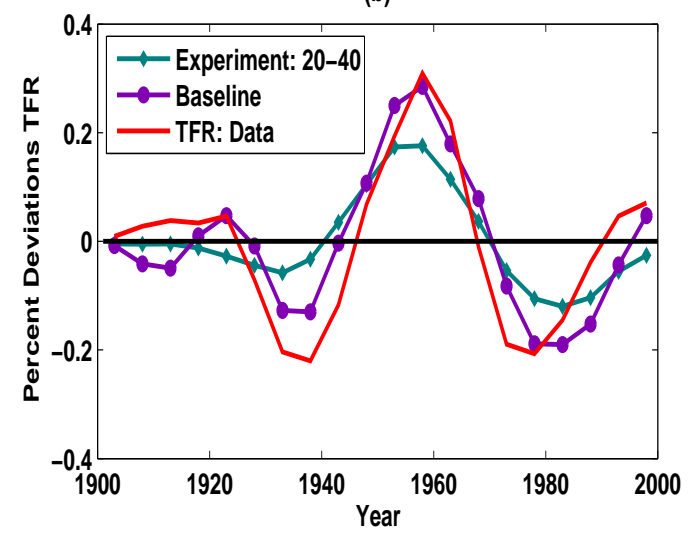

(c)

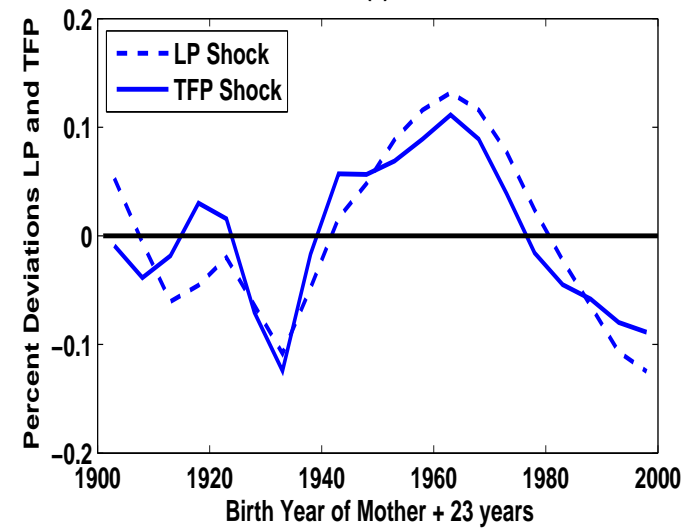

(d)

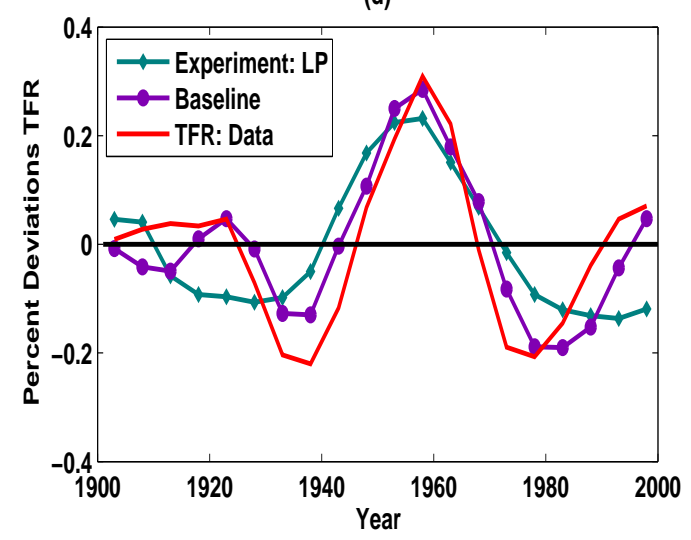

Note: Tables A.1 to A.3 in Appendix A.1 show the exact numbers of shocks, CTFR and TFR responses for the two experiments compared to the baseline.

TFP is that if capital were included in the model, fertility would respond to TFP alongside investment. The argument for using LP is that most people don't own much capital (besides durable goods and houses) so that their fertility response is to changes in LP.

Here we perform the same experiment as in the main text but use deviations from trend in LP instead of TFP. Again, we fit a linear trend through the LP data. The resulting productivity shocks for each cohort are compared to the baseline in Figure 7(c). As can be seen in the figure, there are two main differences between the LP compared to the TFP series of shocks. The very first cohort making fertility decisions in the early 1900s experience a productivity boom and those making fertility decisions in the 1910s and 1920s experience a significant negative shock. Therefore, as shown in Figure $7(d)$, the baby bust is already well underway at this time. Despite the similar size of the shock in the 1930s, fertility decreases 
less in the LP case than in the TFP case. This is because of the mitigating effect of the low young-to-old worker ration due to low fertility in the 1910s. Subsequently, the baby boom starts earlier but is of similar size as the baseline due to the larger LP shock in the 1950s and 1960s compared to TFP. Overall, however, the results are quite similar.

Note that the growth rate of LP in the data is 2.23 percent per year on average, while it is only 1.61 percent per year for TFP. Also, the estimated standard deviation of shocks is 0.08 in most simulations while it is only 0.07 for TFP. In the experiment above, we held these two parameters constant so that we perform only one change at a time and this may have some effect on the outcomes.

\subsection{The effects of including physical capital}

In this section we show that including physical capital as an alternative investment into the model does not change the contemporaneous elasticity to productivity shocks for reasonable calibrations. To do this while keeping the size of the parameter space small, we consider the special case where $w^{2}=0$ and $\theta\left(s^{t}\right)=\theta$ (i.e. the goods cost case) and compare two specifications of the production function for the dynasty:

1. $F\left(K, N^{1}\right)=w^{1} N^{1}$, the simplified version of the baseline case without capital;

2. $F\left(K, N^{1}\right)=K^{\alpha}\left(N^{1}\right)^{1-\alpha}$, the case including capital.

Case 1 is a special case of the model laid out in Section 3 where $w^{2}=0$, and, as such, the results of that section apply automatically. The important equation describing the elasticity of fertility with respect to current productivity shocks is:

$$
\frac{n^{\prime}(s)-E\left(n^{\prime}(s)\right)}{E\left(n^{\prime}(s)\right)}=\frac{\psi s-\psi}{\psi}=s-1
$$

where $\psi=\left(\frac{w}{\theta+\frac{\theta}{\beta(1-\sigma) E\left[\overline{\left.V\left(s^{\prime}\right)\right]}\right.}}\right)$ is independent on $s$.

When capital is included (case 2), the problem the dynasty solves is given by:

$P\left(\gamma, \beta ;\left\{N_{0}^{a}\right\}, K_{0}, s_{0}\right) \quad \max \quad U_{0}^{T}=E\left[\sum_{t=0}^{\infty}(\beta \phi)^{t}\left[\sum_{a=1}^{T} \phi^{1-a} g\left(N_{t}^{a}\left(s^{t-a}\right)\right) u\left(c_{t}^{a}\left(s^{t}\right)\right)\right] \mid s_{0}\right]$

subject to:

$\sum_{a=1}^{3} N_{t}^{a}\left(s^{t-a}\right) c_{t}^{a}\left(s^{t}\right)+\theta N_{t}^{b}\left(s^{t}\right)+K_{t+1}\left(s^{t}\right) \leq s_{t}\left(K_{t}\left(s^{t-1}\right)\right)^{\alpha}\left(\gamma^{t} N_{t}^{1}\left(s^{t-1}\right)\right)^{1-\alpha} ;$

$N_{t}^{1}\left(s^{t-1}\right)=N_{t-1}^{b}\left(s^{t-1}\right)$ is the number of births in period $t-1$;

$N_{t}^{a}\left(s^{t-a}\right)=N_{t-1}^{a-1}\left(s^{t-1-(a-1)}\right)$ for $a=2, \ldots, T$;

$N_{t}^{a}\left(s^{t-a}\right)=0$ for $a>T$; 


$$
N_{0}^{a} \text { given, } a=1, \ldots, T \text {. }
$$

where $s^{t}=\left(s_{0}, s_{1}, \ldots, s_{t}\right)$ is the history of shocks up to and including period $t$.

Under the assumptions that $\phi=1, \eta+\sigma=1$, that costs are in terms of goods, $\theta_{t}=\gamma^{t} \theta$, and shocks are i.i.d. the solution for fertility is given by:

$$
n^{\prime}(s)=\frac{\left(\beta \gamma^{1-\sigma}(1-\sigma) E v\left(k^{\prime}, s^{\prime}\right)\right)^{\frac{1}{\sigma}}}{\left(\left(\gamma k^{\prime}+\theta\right)^{\frac{1}{\sigma}}+\left(\gamma k^{\prime}+\theta\right)\left(\beta \gamma^{1-\sigma}(1-\sigma) E v\left(k^{\prime}, s^{\prime}\right)\right)^{\frac{1}{\sigma}}\right)}[s f(k)+(1-\delta) k]
$$

where $f(k)=F(K / N, 1)$.

Some useful intuition can be gained by examining the case where capital fully depreciates after one 20-year period, $\delta=1$. In this case, since $s^{\prime}$ and $k^{\prime}$ are independent of $s$, we can write $n^{\prime}(s)=\Psi s$, where $\Psi$ independent of $s$, and hence:

$$
\frac{n^{\prime}(s)-E\left(n^{\prime}(s)\right)}{E\left(n^{\prime}(s)\right)}=\frac{\Psi s-\Psi}{\Psi}=s-1
$$

as above. Thus, the elasticity of fertility with respect to a productivity shocks is the same in the two models.

If $\delta<1$, this is not the case, but under realistic assumptions about the annual rate of depreciation the effects are quantitatively similar. To see this, we use the same parameters as in the baseline, except $w^{2}=0$. Further, we follow Jones and Schoonbroodt (2010) and set $\alpha=0.33$ and $\delta=1-(1-0.088)^{20}$. Finally, we calibrate $\theta=0.0214$ to get an annual population growth rate of 0.65 . The wage, $w^{1}$, is not fixed in this model but moves with the marginal product of labor. Therefore, the relevant magnitude to be compared to $\theta=0.19$ in the baseline model, where $w^{1}$ was normalized to $w^{1}=1$, is the cost of children as a fraction of one person's income, $\theta / w^{1}=0.1609$.

We find that, with these parameters, the fertility response to a 1 percent deviation in productivity decreases from 1.0 to 0.9938 . Hence, introducing capital into the model with one period working life tends to dampen the effects of productivity shocks ever so slightly. ${ }^{21}$

\subsection{Three Period Working Life (3PWL)}

While the initial fertility response to productivity shocks is very similar whether $w^{2}>0$ or $w^{2}=0$, dampened oscillations only occur when $w^{2}>0$. Since this property of the model

\footnotetext{
${ }^{21}$ One can show show that in a model with stochastic ageing (useful to obtain reasonable working life lengths while keeping the state space small), the elasticity is larger (smaller) than 1 if the adult survival rate is larger (smaller) than $(1-\delta)$. Since in the present model, survival in the workforce is zero, this is an extreme special case. Thus, introducing capital in general does not change the fertility response to productivity shocks very much.
} 
is important both qualitatively and quantitatively, in this subsection we study whether this feature is robust to more realistic decision periods. To do this, we add one more period of working life and show that similar dampened oscillations occur in this case. Thus, we assume that $w^{3}>0$. Since this increases the number of state variables by one, we abstract from productivity shocks thereby reducing the size of the state-space back to two. In the experiments, we take the initial fertility deviation in and around the 1930s as given and evaluate the oscillations that follow.

Under the assumptions that $\eta=1-\sigma$, and $\phi=1$, as discussed in Section 3.2, $C^{a}=C^{a \prime}$, and the BE in (7) becomes:

$$
V\left(N^{1}, N^{2}, N^{3}\right) \equiv \max _{C, N^{b}} T \frac{C^{1-\sigma}}{1-\sigma}+\beta V\left(N^{1 \prime}, N^{2 \prime}, N^{3 \prime}\right)
$$

subject to:

$$
\begin{aligned}
& T C+\theta N^{b \prime} \leq \sum_{a=1}^{3} w^{a} N^{a} ; \\
& N^{a \prime}=N^{a-1}, \text { for } a=2,3 ; \\
& N^{1 \prime}=N^{b} .
\end{aligned}
$$

The relevant first-order condition here is:

$$
(F O C) \quad L H S\left(n^{\prime}\right)=\frac{\theta}{T \widehat{V}_{1}\left(n^{\prime}, 1, \frac{1}{n}\right)}=\beta\left(\frac{w^{1}+\frac{w^{2}}{n}+\frac{w^{3}}{n n^{-}}-\theta n^{\prime}}{T}\right)^{\sigma}=\operatorname{RHS}\left(n^{\prime}\right),
$$

where $n^{\prime}=N^{b} / N^{1}, n=\frac{N^{1}}{N^{2}}$ and $n^{-}=\frac{N^{2}}{N^{3}}$.

Then, $\operatorname{LHS}\left(n^{\prime}\right)$ is increasing in $n^{\prime}$, with $\operatorname{LHS}(0)=0$ if $E \hat{V}_{1}(0, s)=\infty$. Also, $R H S\left(n^{\prime}\right)$ is decreasing in $n^{\prime}$ with a positive intercept at $n^{\prime}=0$. Thus, there is a unique solution.

As before, RHS shifts down when last period's fertility per capita, $n$, or fertility two periods ago, $n^{-}$, increase. Since $L H S$ is independent of $n^{-}$, it follows that $n^{\prime}$ decreases when $n^{-}$increases and hence, there will necessarily be some oscillatory behavior. This is complicated however since $L H S$ depends on $n$. Which way $L H S$ shifts following an increase in $n$ depends on the cross-partial derivative with respect to $N^{1}$ and $N^{3}, V_{13}$. In particular, if $V_{13}>0$ then LHS shifts up when $n$ increases and, hence, $n^{\prime}$ unambiguously decreases. However, if $V_{13}<0$, then $L H S$ shifts down when $n$ increases and, hence, the overall effect on $n^{\prime}$ is ambiguous.

In what follows, we compare simulations of this model to simulations in the baseline as well as a non-stochastic version of the baseline model (i.e., a special case of the model presented in this section where $w^{3}=0$ ). This intermediate simulation allows us to disentangle how much of the difference comes from having a third period of working life and how much comes from ignoring productivity shocks. 
Figure 8: Percent Deviations in CTFR, 3PWL, Goods Cost

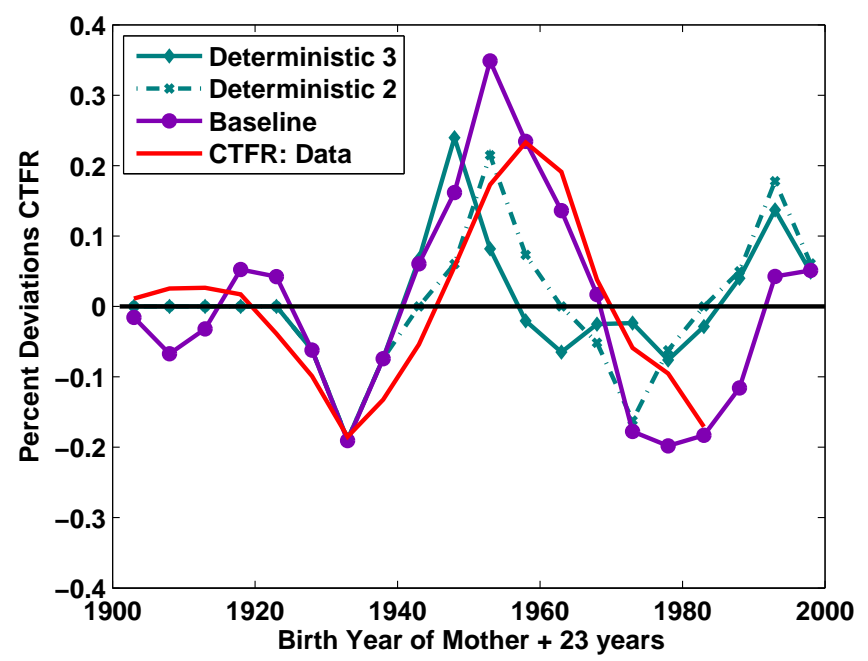

We assume the model period is 15 years. Thus, people work from age 15 to age 60 . Hence, we will have three, instead of four dynasties, five years apart from each other. We keep all the parameters the same as in the baseline, except for $w^{3}$ and the cost of children, $\theta$. We set $w^{3}=1.125$. That is, 45-60 year old workers earn 25 percent less than workers age 30-45. Calibrated costs don't change much from the baseline $(\theta=0.1932$ or $b=0.1927)$. Here, we find $\theta=0.1946$ to match the steady state population growth rate of 0.65 percent per year as before. In the intermediate deterministic version with $w^{3}=0, \theta=0.1901$. Incidentally, note that in all these simulations $V_{13}<0$ so that the effects of last period's fertility on current fertility are ambiguous.

The simulation consists of off balanced growth path dynamics taking the fertility deviation in and around the 1930s from the baseline as given. That is, everything plotted until 1940 is exogenous here and we are interested in the baby boom and the potential for dampened oscillations thereafter. Note that in the deterministic version of the model, whether costs are in terms of time or goods is irrelevant - the only reason why the two cases would differ here is that we use different baby busts from the baseline results as initial conditions.

Figure 8 shows $C T F R$ for all cohorts for goods costs. As can be seen, magnitudes don't differ much between the deterministic model with two versus three periods of working life. Hence, most of the difference to the baseline results are due to the lack of additional productivity shocks, reinforcing the baby boom (and hence subsequent fluctuations). However, the baby boom happens slightly earlier. This is less of an issue of length of the period as it is one of length of generations. In the three period model, parents and children are 15, 
instead of 20 years apart. The analogous results for $C T F R$ with a time cost and $T F R$ with both goods and time costs are similar and hence are not included.

In sum, the dampened oscillations we find in the baseline model are not just an artifact of having two periods working life.

\section{International Evidence}

In this section, we show that countries with a smaller Depression in the 1930s also tend to have smaller baby busts and that those with smaller baby busts tend to have smaller baby booms in the 1950s, conditional on the economic circumstances in the 1950s. Before we start, several data related issues should be addressed. These relate to data availability, detrending methods and dealing with war periods.

Ideally, we would like to use the same measures of fertility and productivity as we do for the U.S.. However, for the 20th century complete TFR series and consistent TFP measures are only available for few countries (see e.g., Chesnais (1992) for TFR and Cette et al. (2009) for TFP). We therefore use Crude Birth Rates (CBR) mostly from Mitchell (1998) and GDP per capita from Barro and Ursua (2008), instead. ${ }^{22}$ This gives us 17 countries for which we have data from 1900 until $1993 .^{23}$

As to detrending, for CBR, we use the same detrending method as we did for TFR in the U.S., namely a Hodrick-Prescott (HP) filter. While for the U.S. a linear detrending method for log-TFP poses few problems, this is not true for all countries we consider. In particular, if one uses linear detrending, countries such as Portugal or Japan show a permanent negative deviation in GDP early in the century and a permanent positive one later on. Besides the linear detrending method, we therefore also use an HP filter in comparison.

Furthermore, the two world wars affected fertility levels in several ways that are unrelated to our mechanism. For example, men being away to fight prevents some women from having children. Typically, there is rapid catching up as soon as the men return, if they do (e.g., see the period 1943-1946 in U.S. data shown in Figure 3). The longer the war involvement and the larger the death rate of soldiers, the more unpredictable this effect on fertility rates becomes. Similar issues emerge for GDP data during war periods. For example, a large

\footnotetext{
${ }^{22}$ CBR data form 1900 to 1993 are obtained from Mitchell (1998) for all countries, except Germany. German data was combined using Chesnais (1992, Appendix A1) for the 1900 to 1943 period and Statistisches Bundesamt (2007) for 1946 to 1993, linearly interpolating 1944 and 1945. All GDP per capita data comes from Barro and Ursua (2008) and is in millions 1990 International Geary-Khamis dollars.

${ }^{23}$ The main issues are. CBR as opposed to TFR is sensitive to mortality in certain groups of the population such as wars which affect total population but not the number of fertile women. GDP per capita as opposed to TFP or LP is only an indirect measure of the productivity of the labor force and therefore corresponds less well to our model.
} 
part of the increase in output in Germany during the war was not for private consumption but rather war related. We therefore also use dummies for war and immediately after war periods to adjust our measures of deviations in CBR and GDP in comparison to deviations resulting from a simple linear trend and the HP filter. ${ }^{24}$

Given these provisos, we are now ready to analyze sizes of depressions, baby busts and baby booms. First, we aim to determine the correlation between the size of the Depression in the 1930s and the size of the baby bust at the time across countries. Since the timing of the Depression was different across countries, we divide the 1930s into two periods: 1930 to 1934 and 1935 to 1939. We then run eight cross-country OLS regressions, one for each time period combined with one of four detrending methods. Let $\widehat{X}_{t}^{i}$ denote the percent deviation from trend in variable $X$ in country $i$ in five-year period $t$.

$$
\widehat{C B R}_{t}^{i}=\lambda_{1, t}+\lambda_{2, t} \widehat{G D P}_{t}^{i}+\varepsilon^{i}
$$

where $t=\{30-34,35-39\}$. The results for each detrending method are given in Table $6 .{ }^{25}$

As can be seen, the coefficient, $\lambda_{2, t}$, is positive for all detrending methods and both time periods. It is larger (with a lower $p$-value) whenever an HP filter is used rather than linear detrending and whenever the effects of wars are taken into account in detrending. Also, for most detrending methods, $\lambda_{2, t}$ is larger in the early 1930s than in the late $1930 \mathrm{~s}^{26}$

Second, we aim to determine whether a larger baby bust in the 1930s implies a larger baby boom in the $1950 \mathrm{~s}$, controlling for the GDP deviation in the 1950s. To do this, we run eight cross-country OLS regressions, one for each time period combined with one of four detrending methods.

$$
\widehat{C B R}_{t}^{i}=\lambda_{3, t}+\lambda_{4, t} \widehat{C B R}_{t-20}^{i}+\lambda_{5, t} \widehat{G D P}_{t}^{i}+\varepsilon^{i}
$$

where $t=\{50-54,55-59\}$. The results for each detrending method are given in Table $7 .{ }^{27}$

As can be seen, the coefficient, $\lambda_{4, t}$, is negative for all detrending methods and both time periods. It is larger in absolute value (with a lower $p$-value) whenever an HP filter is used rather than linear detrending and, for the late 1950s, whenever the effects of wars are taken into account in detrending. Also, $\lambda_{4, t}$ is larger in the early 1930 s than in the late

\footnotetext{
${ }^{24}$ For details on detrending procedures, see Appendix A.3.

${ }^{25}$ Tables A.5 to A.6 Appendix A.3 show the inputs into these regressions, namely percent deviations from trend in $C B R$ and GDP in the 1930s for each country and each detrending method.

${ }^{26}$ Observations relating to depressions and busts across countries leading to these regression results are given in Appendix A.3.1.

${ }^{27}$ Tables A.7 to A.8 Appendix A.3 (NOT for publication) show the inputs into these regressions, namely percent deviations from trend in $C B R$ in the 1930s and 1950s and in GDP in the 1950s for each country and each detrending method.
} 
Table 6: Cross-Country: Depressions and Busts, 1930s

\begin{tabular}{|c|c|c|c|c|c|}
\hline \multirow{2}{*}{$\begin{array}{l}\text { Dependent } \\
\text { Variable }\end{array}$} & \multirow{2}{*}{$\begin{array}{l}\text { Independent } \\
\text { Variable }\end{array}$} & \multicolumn{4}{|c|}{ Detrending Method } \\
\hline & & Linear & $\mathrm{HP}$ & $\begin{array}{l}\text { Linear } \\
\text { No war }\end{array}$ & $\begin{array}{c}\text { HP } \\
\text { No war }\end{array}$ \\
\hline \multirow[t]{2}{*}{$\widehat{C B R}_{30-34}^{i}$} & Constant $\left(\lambda_{1,30-34}\right)$ & -0.0522 & -0.0839 & -0.0365 & -0.0446 \\
\hline & $\begin{array}{l}\widehat{G D P}_{30-34}^{i}\left(\lambda_{2,30-34}\right) \\
(p \text {-value })\end{array}$ & $\begin{array}{l}0.3512 \\
(0.059)\end{array}$ & $\begin{array}{l}0.4253 \\
(0.008)\end{array}$ & $\begin{array}{l}0.3933 \\
(0.084)\end{array}$ & $\begin{array}{l}0.6480 \\
(0.008)\end{array}$ \\
\hline \multirow[t]{2}{*}{$\widehat{C B R}_{35-39}^{i}$} & Constant $\left(\lambda_{1,35-39}\right)$ & -0.0856 & -0.1211 & -0.0716 & -0.0806 \\
\hline & $\begin{array}{l}\widehat{G D P}_{35-39}^{i}\left(\lambda_{2,35-39}\right) \\
(p \text {-value })\end{array}$ & $\begin{array}{l}0.2118 \\
(0.441)\end{array}$ & $\begin{array}{l}0.5743 \\
(0.005)\end{array}$ & $\begin{array}{l}0.2482 \\
(0.335)\end{array}$ & $\begin{array}{l}0.5554 \\
(0.004)\end{array}$ \\
\hline
\end{tabular}

Table 7: Cross-Country: Busts and Booms, 1950s vs. 1930s

\begin{tabular}{|c|c|c|c|c|c|}
\hline \multirow{2}{*}{$\begin{array}{l}\text { Dependent } \\
\text { Variable }\end{array}$} & \multirow{2}{*}{$\begin{array}{l}\text { Independent } \\
\text { Variable }\end{array}$} & \multicolumn{4}{|c|}{ Detrending Method } \\
\hline & & Linear & HP & $\begin{array}{l}\text { Linear } \\
\text { No war }\end{array}$ & $\begin{array}{c}\text { HP } \\
\text { No war }\end{array}$ \\
\hline \multirow[t]{3}{*}{$\widehat{C B R}_{50-54}^{i}$} & Constant $\left(\lambda_{3,50-54}\right)$ & 0.0477 & 0.0203 & 0.0853 & 0.0506 \\
\hline & $\begin{array}{l}\widehat{C B R}_{30-34}^{l}\left(\lambda_{4,50-54}\right) \\
\text { (p-value) }\end{array}$ & $\begin{array}{l}-0.2795 \\
(0.229)\end{array}$ & $\begin{array}{c}-0.3680 \\
(0.058)\end{array}$ & $\begin{array}{r}-0.1527 \\
(0.634)\end{array}$ & $\begin{array}{r}-0.2792 \\
(0.372)\end{array}$ \\
\hline & $\begin{array}{l}\widehat{G D P}_{50-54}^{i}\left(\lambda_{5,50-54}\right) \\
(p \text {-value })\end{array}$ & $\begin{array}{l}0.2181 \\
(0.171)\end{array}$ & $\begin{array}{l}0.3316 \\
(0.092)\end{array}$ & $\begin{array}{l}0.2571 \\
(0.208)\end{array}$ & $\begin{array}{l}0.2034 \\
(0.428)\end{array}$ \\
\hline \multirow[t]{3}{*}{$\widehat{C B R}_{55-59}^{i}$} & Constant $\left(\lambda_{3,55-59}\right)$ & 0.0960 & 0.0296 & 0.0680 & 0.0296 \\
\hline & $\begin{array}{l}\widehat{C B R}_{35-39}^{i}\left(\lambda_{4,55-59}\right) \\
\text { (p-value) }\end{array}$ & $\begin{array}{r}-0.0973 \\
(0.714)\end{array}$ & $\begin{array}{r}-0.2854 \\
(0.181)\end{array}$ & $\begin{array}{c}-0.4048 \\
(0.143)\end{array}$ & $\begin{array}{l}-0.5748 \\
(0.020)\end{array}$ \\
\hline & $\begin{array}{l}\widehat{G D P}_{55-59}^{i}\left(\lambda_{5,55-59}\right) \\
(p \text {-value })\end{array}$ & $\begin{array}{l}0.6052 \\
(0.012)\end{array}$ & $\begin{array}{l}1.0424 \\
(0.004)\end{array}$ & $\begin{array}{l}0.4029 \\
(0.045)\end{array}$ & $\begin{array}{l}0.4887 \\
(0.046)\end{array}$ \\
\hline
\end{tabular}


1930s when the effects of wars are not taken into account in detrending, smaller when they are. Similar to $\lambda_{2, t}$, the coefficient $\lambda_{5, t}$ is positive for all detrending methods and both time periods. However, $p$-values are larger, especially in the early $1950 \mathrm{~s}^{28}$

In sum then, international evidence on the sizes of depressions and baby busts in the 1930s strongly supports our theory while the evidence for the size of the subsequent baby boom, though rightly signed, is somewhat weaker.

\section{Concluding remarks}

In this paper, we have studied the properties of models of fertility choice with dynastic altruism in which both aggregate shocks and multiple generations are present. We have shown that in simple versions of this class of models, fertility is procyclical and has dampened oscillations when perturbed away from the steady state. Moreover, these effects are quantitatively significant. In calibrated simulations of the model, we find that in response to a negative shock to income like the Great Depression, the decline in fertility in the model is between 40 and 70 percent of the decline actually seen in the data. Moreover, because of a (mild) productivity boom in the 1950s and early 1960s in conjunction with the oscillatory effects discussed above, the model accounts for between 60 and 90 percent of the Baby Boom. The key parameter determining the quantitative findings is the nature of the cost of children - goods versus time.

\footnotetext{
${ }^{28}$ Observations relating to busts and booms across countries leading to these regression results are given in Appendix A.3.1.
} 


\section{References}

Albanesi, Stefania and Claudia Olivetti, "Maternal Health and the Baby Boom," Working Paper 16146, National Bureau of Economic Research 2010.

Barro, Robert J. and Gary S. Becker, "Fertility Choice in a Model of Economic Growth," Econometrica, 1989, 57 (2), 481-501.

- and Jose F. Ursua, "Macroeconomic Crises since 1870," Working Paper 13940, National Bureau of Economic Research 2008. Data available at http://www.economics.harvard.edu/faculty/barro/data_sets_barro.

Becker, Gary S. and Robert J. Barro, "A Reformulation of the Theory of Fertility," Quarterly Journal of Economics, 1988, 103 (1), 1-25.

Butz, William P. and Michael P. Ward, "The Emergence of Countercyclical U.S. Fertility," The American Economic Review, 1979, 69 (3), 318-328.

Caucutt, Elizabeth M., Nezih Guner, and John Knowles, "Why do Women Wait? Matching, Wage Inequality, and The Incentives for Fertility Delay," The Review of Economic Dynamics, 2002, 5 (4), 815-855.

Cette, Gilbert, Yusuf Kocoglu, and Jacques Mairesse, "Productivity Growth and Levels in France, Japan, the United Kingdom and the United States in the Twentieth Century," Working Paper 15577, National Bureau of Economic Research 2009.

Chari, V. V., Patrick J. Kehoe, and Ellen R. McGrattan, "Business Cycle Accounting," Econometrica, 2007, 75 (3), 781-836.

Chesnais, Jean Claude, The Demographic Transition: Stages, Patterns, and Economic Implications: A Longitudinal Study of Sixty-seven Countries Covering the Period 17201984, Oxford University Press, 1992.

Doepke, Matthias, Moshe Hazan, and Yishay Maoz, "The Baby Boom and World War II: A Macroeconomic Analysis," Working Paper 13707, National Bureau of Economic Research December 2007.

Easterlin, Richard A., "The American Baby Boom in Historical Perspective," The American Economic Review, 1961, 51 (5), 869-911.

_, Population, Labor Force, and Long Swings in Economic Growth, National Bureau of Economic Research, 1968. 
_, "What Will 1984 Be Like? Socioeconomic Implications of Recent Twists in Age Structure," Demography, 1978, 15 (4), 397-432.

_, Birth and Fortune, 2nd ed., University of Chicago Press, Chicago, IL, 1987.

Feichtinger, Gustav and Engelbert J. Dockner, "Capital Accumulation, Endogenous Population Growth, and Easterlin Cycles," Journal of Population Economics, 1990, 3, 73-87.

- and Gerhard Sorger, "Self-Generated Fertility Waves in a Non-Linear Continuous Overlapping Generations Model," Journal of Population Economics, 1989, 2, 267-280.

Greenwood, Jeremy, Ananth Seshadri, and Guillaume Vandenbroucke, "The Baby Boom and Baby Bust," The American Economic Review, 2005, 95 (1), 183-207.

Haines, Michael R., "The Population of the United States, 1790-1920," Historical Working Paper 56, National Bureau of Economic Research 1994.

Hansen, Gary D., "The Cyclical and Secular Behaviour of the Labour Input: Comparing Efficiency Units and Hours Worked," Journal of Applied Econometrics, 1993, 8 (1), 71-80.

Huggett, Mark, "Wealth distribution in life-cycle economies," Journal of Monetary Economics, 1996, 38 (3), 469-494.

Jones, Larry E. and Alice Schoonbroodt, "Complements versus Substitutes and Trends in Fertility Choice in Dynastic Models," International Economic Review, 2010, 51 (3), 671-699.

_ and Michèle Tertilt, "An Economic History of Fertility in the U.S.: 1826-1960," in Peter Rupert, ed., Frontiers of Family Economics, Vol. 1, Emerald Press, 2008.

- and Rodolfo E. Manuelli, "A Convex Model of Equilibrium Growth: Theory and Policy Implications," Journal of Political Economy, 1990, 98 (5), 1008-1038.

Lee, Ronald, "The Formal Dynamics of Controlled Populations and the Echo, the Boom and the Bust," Demography, 1974, 11 (4), 563-585.

Lee, Ronald D., "Population Dynamics," in S.N. Durlauf and L.E. Blume, eds., The New Palgrave Dictionary of Economics, Basingstoke: Palgrave Macmillan, 2008.

Macunovich, Diane J., "Fertility and the Easterlin Hypothesis: An Assessment of the Literature," Journal of Population Economics, 1998, 11, 53-111. 
- and Richard A. Easterlin, "Easterlin Hypothesis," in S.N. Durlauf and L.E. Blume, eds., The New Palgrave Dictionary of Economics, Basingstoke: Palgrave Macmillan, 2008.

Manuelli, Rodolfo E. and Ananth Seshadri, "Explaining International Fertility Differences," Quarterly Journal of Economics, 2009, 124 (2), 771-807.

Mateos-Planas, Xavier, "The Demographic Transition in Europe: A Neoclassical Dynastic Approach," Review of Economic Dynamics, July 2002, 5 (3), 646-680.

Mitchell, Brian R., International Historical Statistics: Europe, 1750-1993, New York, N.Y.: Stockton Press, 1998.

Rebelo, Sergio, "Long-Run Policy Analysis and Long-Run Growth," Journal of Political Economy, 1991, 99 (3), 500-521.

Samuelson, Paul A., "An Economist's Non-Linear Model of Self-Generated Fertility Waves," Population Studies, 1976, 30 (2), 243-247.

Scholz, John Karl and Ananth Seshadri, "Children and Household Wealth," Working Paper, University of Wisconsin 2009.

Schoonbroodt, Alice and Michèle Tertilt, "Property Rights and Efficiency in OLG Models with Endogenous Fertility," Working Paper, University of Southampton 2010.

Sobotka, Tomas, Vegard Skirbekk, and Dimiter Philipov, "Economic Recession and Fertility in the Developed World. A Literature Review," Working Paper, Vienna Institute of Demography, Vienna, Austria 2010.

Sommer, Kamila, "Fertility Choice in a Life Cycle Model with Idiosyncratic Uninsurable Earnings Risk," Working Paper, Georgetown University 2010.

Statistisches Bundesamt, Wiesbaden, "Zusammenfassende Übersichten, 1 Eheschlieungen, Geborene und Gestorbene, 1.4 Deutschland, Verhltniszahlen," 2007. http://www.destatis.de/jetspeed/portal/cms/Sites/destatis/Internet/DE/Content/ Statistiken/Bevoelkerung/EheschliessungenScheidungen/Tabellen/Content100/ EheschliessungenGeboreneGestorbene,templateId=renderPrint.psml. 


\section{A Appendix}

\section{A.1 Tables of shocks and fertility responses in Sections 5.1 and 5.2}

Table A.1: Productivity Shocks (in percent) for Experiments

\begin{tabular}{l|r|r|r}
\hline \hline \multirow{2}{*}{ Cohort } & \multicolumn{2}{|c|}{ TFP } & \multicolumn{1}{c}{ LP } \\
\cline { 2 - 4 } & Baseline & Age 20-40 & Age 20-30 \\
\hline$c_{1}$ & -0.90 & -1.10 & 5.30 \\
$c_{2}$ & -3.85 & -0.14 & -0.63 \\
$c_{3}$ & -1.84 & 0.14 & -6.04 \\
$c_{4}$ & 3.02 & -1.75 & -4.55 \\
$c_{5}$ & 1.58 & -5.17 & -2.00 \\
$c_{6}$ & -7.06 & -4.11 & -6.41 \\
$c_{7}$ & -12.43 & -3.09 & -10.84 \\
$c_{8}$ & -1.68 & 2.26 & -4.79 \\
$c_{9}$ & 5.72 & 6.59 & 1.65 \\
$c_{10}$ & 5.65 & 7.57 & 4.80 \\
$c_{11}$ & 6.89 & 9.31 & 8.86 \\
$c_{12}$ & 8.92 & 9.21 & 11.60 \\
$c_{13}$ & 11.14 & 7.81 & 13.17 \\
$c_{14}$ & 8.91 & 3.95 & 11.59 \\
$c_{15}$ & 3.90 & -0.03 & 7.73 \\
$c_{16}$ & -1.56 & -3.43 & 2.39 \\
$c_{17}$ & -4.49 & -5.97 & -2.25 \\
$c_{18}$ & -5.82 & -6.58 & -6.44 \\
$c_{19}$ & -7.97 & -7.71 & -10.69 \\
$c_{20}$ & -8.86 & -8.62 & -12.48 \\
& & & \\
\hline \hline
\end{tabular}


Table A.2: CTFR response (in percent) from Experiments

\begin{tabular}{l|rr|rr|rr}
\hline \hline \multirow{2}{*}{ Cohort } & \multicolumn{2}{|c|}{ Baseline } & \multicolumn{2}{l}{ TFP, age 20-40 } & \multicolumn{2}{l}{ LP, age $20-30$} \\
\cline { 2 - 7 } & & & & & & \\
& & & & & & \\
& & & & \\
$c_{1}$ & -1.57 & -0.94 & -1.92 & -1.15 & 9.22 & 5.44 \\
$c_{2}$ & -6.71 & -4.06 & -0.25 & -0.15 & -1.09 & -0.65 \\
$c_{3}$ & -3.20 & -1.93 & 0.25 & 0.15 & -10.54 & -6.42 \\
$c_{4}$ & 5.25 & 3.12 & -3.05 & -1.83 & -7.94 & -4.81 \\
$c_{5}$ & 4.23 & 2.52 & -7.31 & -4.43 & -11.05 & -6.77 \\
$c_{6}$ & -6.20 & -3.79 & -6.94 & -4.20 & -10.24 & -6.23 \\
$c_{7}$ & -19.05 & -11.79 & -5.61 & -3.39 & -9.30 & -5.78 \\
$c_{8}$ & -7.41 & -4.50 & 6.87 & 4.07 & -0.85 & -0.56 \\
$c_{9}$ & 6.04 & 3.55 & 19.12 & 11.12 & 14.36 & 8.40 \\
$c_{10}$ & 16.17 & 9.50 & 20.47 & 11.89 & 19.23 & 11.16 \\
$c_{11}$ & 34.88 & 19.68 & 22.10 & 12.80 & 25.56 & 14.86 \\
$c_{12}$ & 23.43 & 13.56 & 9.63 & 5.60 & 21.02 & 12.23 \\
$c_{13}$ & 13.61 & 7.93 & -2.17 & -1.57 & 9.96 & 5.66 \\
$c_{14}$ & 1.68 & 0.75 & -9.23 & -5.85 & 3.78 & 1.96 \\
$c_{15}$ & -17.76 & -11.34 & -16.58 & -10.41 & -6.55 & -4.44 \\
$c_{16}$ & -19.82 & -12.48 & -13.73 & -8.38 & -12.08 & -7.63 \\
$c_{17}$ & -18.31 & -11.31 & -8.51 & -4.93 & -12.02 & -7.21 \\
$c_{18}$ & -11.58 & -6.83 & -2.79 & -1.52 & -14.36 & -8.55 \\
$c_{19}$ & 4.25 & 2.67 & 3.30 & 1.94 & -12.93 & -7.52 \\
$c_{20}$ & 5.10 & 2.90 & -1.74 & -1.26 & -10.79 & -6.50 \\
& & & & & & \\
\hline \hline & & & & & & \\
\hline
\end{tabular}


Table A.3: TFR response (in percent) from Experiments

\begin{tabular}{l|rr|rr|rr}
\hline \hline \multirow{2}{*}{ Time } & \multicolumn{2}{|c|}{ Baseline } & \multicolumn{2}{|l}{ TFP, age 20-40 } & \multicolumn{2}{c}{ LP, age $20-30$} \\
\cline { 2 - 7 } Period & & & & & & \\
\cline { 2 - 7 } & Goods & Time & Goods & Time & Goods & Time \\
\hline $1901-05$ & -0.78 & -0.47 & -0.48 & -0.29 & 4.61 & 2.72 \\
$1906-10$ & -4.14 & -2.50 & -0.54 & -0.32 & 4.06 & 2.39 \\
$1911-15$ & -4.96 & -2.99 & -0.48 & -0.29 & -5.82 & -3.54 \\
$1916-20$ & 1.03 & 0.60 & -1.24 & -0.75 & -9.24 & -5.61 \\
$1921-25$ & 4.71 & 2.80 & -2.72 & -1.65 & -9.66 & -5.90 \\
$1926-30$ & -0.84 & -0.59 & -4.43 & -2.69 & -10.66 & -6.51 \\
$1931-35$ & -12.74 & -7.84 & -5.80 & -3.51 & -9.79 & -6.02 \\
$1936-40$ & -12.99 & -8.06 & -3.31 & -2.01 & -5.01 & -3.13 \\
$1941-45$ & -0.34 & -0.25 & 3.46 & 2.06 & 6.63 & 3.84 \\
$1946-50$ & 10.70 & 6.38 & 10.44 & 6.15 & 16.81 & 9.78 \\
$1951-55$ & 25.01 & 14.42 & 17.37 & 10.12 & 22.41 & 13.02 \\
$1956-60$ & 28.54 & 16.42 & 17.61 & 10.28 & 23.19 & 13.49 \\
$1961-65$ & 17.94 & 10.47 & 11.40 & 6.67 & 15.10 & 8.71 \\
$1966-70$ & 7.85 & 4.41 & 3.67 & 2.07 & 6.81 & 3.77 \\
$1971-75$ & -8.23 & -5.37 & -5.41 & -3.46 & -1.52 & -1.32 \\
$1976-80$ & -18.86 & -11.93 & -10.56 & -6.60 & -9.26 & -6.00 \\
$1981-85$ & -19.00 & -11.85 & -11.99 & -7.35 & -12.05 & -7.43 \\
$1986-90$ & -15.24 & -9.19 & -10.37 & -6.22 & -13.15 & -7.86 \\
$1991-95$ & -4.35 & -2.33 & -5.55 & -3.20 & -13.68 & -8.06 \\
$1996-00$ & 4.70 & 2.79 & -2.58 & -1.49 & -11.89 & -7.03 \\
& & & & & & \\
\hline \hline
\end{tabular}




\section{A.2 Additional experiment relating to Section 5.1}

A second alternative is to use the average productivity shock ages 15 to 45, weighted by the percentage of all births born to the particular age-groups. This takes the typical timing of births into account. In addition, even if the shock we attribute to any individual cohort does not correspond to the actual 20 year shock they experienced, it leaves the aggregate shock in any five year period at its correct level (since different dynasties receive a fraction of it). To see this, consider Table A.4. Now, consider a cohort that is age 15-19 in 1901-05. The

Table A.4: Percent of total births that occur to five-year age group (average 1940-70)

\begin{tabular}{l|r|r|r|r|r|r|r}
\hline \hline Age group & $1: 15-19$ & $2: 20-24$ & $3: 25-29$ & $4: 30-34$ & $5: 35-39$ & $6: 40-44$ & $7: 45-49$ \\
\% all births & 12.45 & 32.84 & 27.19 & 16.54 & 8.40 & 2.39 & 0.18 \\
\hline \hline
\end{tabular}

seven relevant shocks are from 1901-05 to 1931-35. However, the weight of the shock in the beginning of the Great Depression, 1931-35, will only receive weight 0.0018. The next cohort of women, age 15-19 in 1906-10 will receive a weight of 0.0239 for the same shock and so on. Finally, the cohort age 15-19 in 1931-35 will receive a weight 0.1245 for this shock. Hence, 100 percent of the Great Depression shock will be accounted for as part of 7 distinct cohort shocks. The results from this experiment can be seen in Figure A.1. The results are quite similar, albeit smoother and somewhat smaller, to the baseline described in Section 4.3.

Note, however, that this alternative does not allow our cohorts to adjust their timing of births to shocks experienced at different ages while fertile. As shown in Doepke et al. (2007), timing of births for any given cohort did change during the bust-boom-bust episode, albeit to a limited extent. As mentioned before, decreasing the length of the period in order to start addressing this issue would significantly increase the state space. In addition, it would to require a bulk of additional assumptions and complicate the theoretical results. We therefore chose to concentrate on the two simple mechanisms from Proposition 1 in the main paper and leave this issue to future research.

\section{A.3 Details on detrending methods used in Section 6}

CBR deviations reported in Table A.5, columns 1 and 2, and Table A.7, columns 1 to 4, and used in regressions reported in Tables 6 and 7, columns 1 and 2, are obtained by running an HP filter (smoothing parameter, $w=20,000$ ) on annual CBR data for each country with implied annual deviations averaged over five years. 
Figure A.1: Percent Deviations in TFR, Age 15-45, weighted

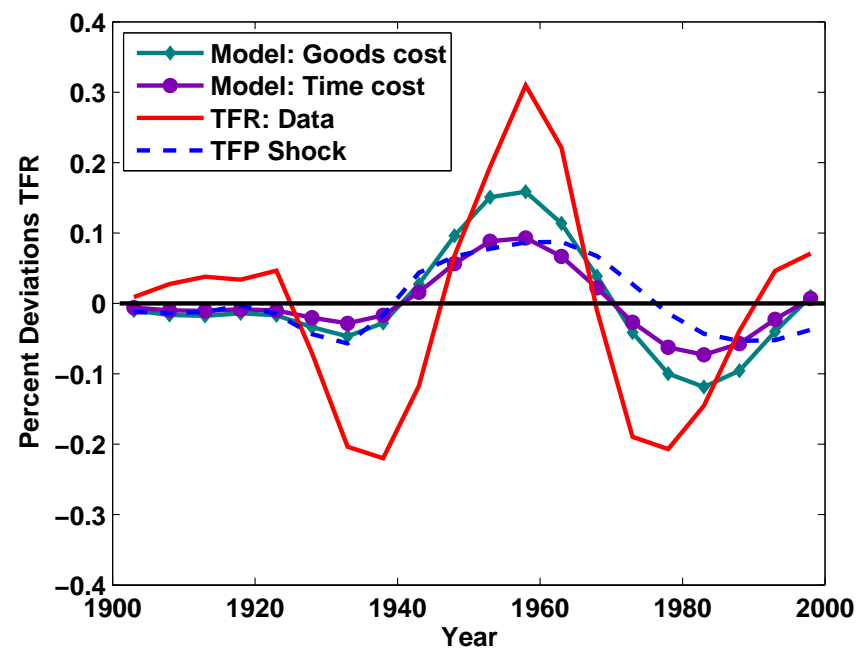

GDP deviations reported in Table A.5, columns 3 and 4, and Table A.7, columns 5 and 6, and used in regressions reported in Tables 6 and 7, column 1, are obtained by running an OLS regression of the form $\ln G D P_{t}^{i}=\alpha_{0}^{i}+\alpha_{1}^{i} t+\varepsilon_{t}^{i}$ using annual GDP per capita data for each country, $i$, with five-year deviations computed as $\widehat{G D P}_{s-(s+4)}^{i}=\exp \left[\ln \left(\sum_{t=s}^{s+4} e^{\varepsilon_{t}^{i}}\right)-\mu^{i}\right]$ where $\mu^{i}=E\left(\ln \left(\sum_{t=s}^{s+4} e^{\epsilon_{t}^{i}}\right)\right)$.

GDP deviations reported in Table A.5, columns 5 and 6, and Table A.7, columns 7 and 8 , and used in regressions reported in Tables 6 and 7, column 2, are obtained by running an HP filter (smoothing parameter, $w=20,000$ ) on $\ln G D P$ per capita data (smoothing parameter, $w=20,000)$ for each country, $i$, with five-year deviations computed as above using HP residuals.

To account for the effect of wars, we first create four dummy variables, $d_{k}^{i}, k=1, \ldots 4$, for the time periods $t=\{1: 1914-1918,2: 1919-1923,3: 1940-1945,4: 1946-1950\}$ for each country, $i$. We then run the following time series regression on annual data for $X^{i}=\left\{G D P^{i}, C B R^{i}\right\}$ for each country, $i$.

$$
\ln X_{t}^{i}=\alpha_{0}^{i}+\alpha_{1}^{i} t+\sum_{k=1}^{4} \alpha_{k+1}^{i} d_{k t}^{i}+\varepsilon_{t}^{i}
$$

We then compute $\widetilde{X}_{t}^{i}=\exp \left[\ln X_{t}^{i}-\sum_{k=1}^{4} \alpha_{k+1} d_{k t}^{i}\right]$. The deviations used in regressions reported in Tables 6 and 7, columns 3 and 4 , are then calculated exactly as those in columns 1 and 2, except that we use $\widetilde{X}_{t}^{i}$ instead of $X_{t}^{i}$. 


\section{A.3.1 Observations about Cross-Country Busts and Booms}

From Tables A.5 and A.6 we make the following observations. Countries that, similar to the U.S., have large depressions and large baby busts throughout the 1930s are Canada, Australia and New Zealand. Countries with slightly smaller depressions and baby busts are Germany, the U.K. and France. Note that France has a late depression (late 1930s) and correspondingly, a late baby bust while Germany and the U.K. have large depressions in the early 1930s and correspondingly large baby busts early on. For the Netherlands, Belgium and Switzerland, the depression is noticeable only if the effects of wars are taken into account when detrending (Table A.6). For Southern European countries, Italy, Portugal and Spain, both the depression as well as the baby bust are small or non-existent, depending on detrending method. For Northern European countries, Denmark, Norway and Sweden, large baby busts can be observed, despite the fact that the depression is small or non-existent depending on detrending method. These observations rationalize results in Table 6 .

Because of the last observation, when analyzing baby booms in the main text, we use

$\widehat{C B R}_{1930 s}$ rather than $\widehat{G D P}_{1930 s}$ as the independent variable. This allows us to determine whether baby busts are correlated with subsequent baby booms, independently of their cause.

Indeed, from Tables A.7 and A.8, all three Northern countries display substantial baby booms in the 1950s, though potentially mitigated by a recession in the 1950s. Similarly, Central European and Southern European countries, all have small baby booms in the late 1950s with GDP significantly below trend for most detrending methods. Southern European countries have somewhat of a baby boom. The largest baby booms are to be observed in the U.S., Canada, Australia and New Zealand where the baby bust was particularly large. These observations rationalize the weaker results in Table 7.

\section{A.4 Sensitivity to changes in parameters}

we compute how elasticities and fertility levels change when we change parameter values in Table 2. Results are reported in Table A.9. For each parameter change, we report two cases. First, we give results in the case where costs of children remain at their baseline value, which leads to varying fertility levels in steady state. Second, we recalibrate to the target population growth by adjusting costs of children accordingly. Results show that within a reasonable range of parameter values, the elasticity of contemporaneous fertility to productivity shocks ranges from 1.6 to 1.9 in the goods cost case and 0.95 to 1.2 for the time cost case, while the elasticity of lagged fertility ranges from -1.25 to -1.9 in the goods cost case and -0.7 to -1.2 for the time cost case, whether we recalibrate or not. Thus, the results don't seem to be very sensitive to parameter choices. 
Table A.5: Depressions and Baby Busts across Countries

\begin{tabular}{l|rr|rr|cr}
\hline \hline \multirow{2}{*}{ Country } & \multicolumn{2}{|c|}{$\widehat{C B R}_{1930 s}$} & $\widehat{G D P}_{1930 s}$, Linear & \multicolumn{2}{|c}{$\widehat{G D P}_{1930 s}, \mathrm{HP}$} \\
\cline { 2 - 7 } & $1930-34$ & $1935-39$ & $1930-34$ & $1935-39$ & $1930-34$ & $1935-39$ \\
\hline U.S. & -0.167 & -0.184 & -0.264 & -0.209 & -0.206 & -0.149 \\
Canada & -0.127 & -0.183 & -0.256 & -0.254 & -0.179 & -0.166 \\
Australia & -0.184 & -0.185 & -0.211 & -0.124 & -0.150 & -0.043 \\
New Zealand & -0.181 & -0.169 & -0.243 & -0.090 & -0.177 & -0.010 \\
& & & & & & \\
U.K. & -0.123 & -0.111 & -0.115 & -0.059 & -0.058 & 0.012 \\
Germany & -0.137 & 0.087 & -0.296 & -0.076 & -0.168 & 0.126 \\
France & -0.005 & -0.134 & -0.014 & -0.176 & 0.137 & -0.001 \\
& & & & & & \\
Netherlands & -0.084 & -0.121 & 0.016 & -0.052 & 0.111 & 0.079 \\
Belgium & 0.009 & -0.081 & 0.039 & -0.046 & 0.168 & 0.112 \\
Switzerland & -0.088 & -0.135 & 0.017 & -0.061 & 0.091 & 0.024 \\
& & & & & & \\
Italy & -0.004 & -0.003 & -0.080 & -0.060 & 0.019 & 0.094 \\
Spain & 0.059 & -0.116 & -0.041 & -0.081 & 0.039 & 0.030 \\
Portugal & 0.008 & -0.031 & -0.074 & -0.178 & 0.086 & 0.007 \\
Denmark & -0.135 & -0.094 & 0.027 & -0.008 & 0.093 & 0.078 \\
Norway & -0.184 & -0.189 & -0.026 & 0.001 & 0.040 & 0.089 \\
Sweden & -0.172 & -0.128 & -0.083 & -0.014 & -0.022 & 0.053 \\
Japan & 0.027 & -0.010 & -0.111 & -0.083 & 0.029 & 0.138 \\
& & & & & & \\
\hline \hline
\end{tabular}


Table A.6: Depressions and Baby Busts across Countries, No War

\begin{tabular}{l|rr|rr|rr}
\hline \hline \multirow{2}{*}{ Country } & \multicolumn{2}{|c|}{$\widehat{C B R}_{1930 s}$} & $\widehat{G D P}_{1930 s}$, Linear & \multicolumn{2}{|c}{$\widehat{G D P}_{1930 s}, \mathrm{HP}$} \\
\cline { 2 - 7 } & $1930-34$ & $1935-39$ & $1930-34$ & $1935-39$ & $1930-34$ & $1935-39$ \\
\hline U.S. & -0.144 & -0.163 & -0.258 & -0.202 & -0.192 & -0.129 \\
Canada & -0.104 & -0.158 & -0.252 & -0.251 & -0.177 & -0.165 \\
Australia & -0.170 & -0.173 & -0.211 & -0.124 & -0.152 & -0.047 \\
New Zealand & -0.166 & -0.147 & -0.250 & -0.098 & -0.191 & -0.032 \\
& & & & & & \\
U.K. & -0.137 & -0.126 & -0.111 & -0.055 & -0.055 & 0.016 \\
Germany & -0.189 & 0.027 & -0.305 & -0.086 & -0.178 & 0.129 \\
France & -0.047 & -0.160 & -0.107 & -0.251 & -0.041 & -0.181 \\
& & & & & & \\
Netherlands & -0.065 & -0.094 & -0.064 & -0.124 & -0.035 & -0.085 \\
Belgium & -0.062 & -0.141 & -0.088 & -0.156 & -0.043 & -0.105 \\
Switzerland & -0.101 & -0.139 & -0.036 & -0.107 & 0.001 & -0.067 \\
& & & & & & \\
Italy & -0.021 & -0.013 & -0.093 & -0.076 & -0.028 & 0.017 \\
Spain & 0.046 & -0.126 & -0.059 & -0.098 & 0.003 & -0.011 \\
Portugal & 0.013 & -0.024 & -0.119 & -0.217 & -0.005 & -0.090 \\
Denmark & -0.126 & -0.073 & -0.016 & -0.047 & 0.015 & -0.011 \\
Norway & -0.163 & -0.169 & -0.055 & -0.028 & -0.017 & 0.018 \\
Sweden & -0.147 & -0.097 & -0.106 & -0.038 & -0.065 & 0.004 \\
Japan & 0.080 & 0.052 & -0.112 & -0.087 & 0.010 & 0.100 \\
& & & & & & \\
\hline \hline
\end{tabular}


Table A.7: Baby Busts and Baby Booms across Countries

\begin{tabular}{|c|c|c|c|c|c|c|c|c|}
\hline \multirow[t]{2}{*}{ Country } & \multicolumn{2}{|c|}{$\widehat{C B R}_{1950 \mathrm{~s}}$} & \multicolumn{2}{|c|}{$\widehat{C B R}_{1930 s}$} & \multicolumn{2}{|c|}{$\widehat{G D P}_{1950 s}$, Linear } & \multicolumn{2}{|c|}{$\widehat{G D P}_{1950 s}, \mathrm{HP}$} \\
\hline & $1950-55$ & $1955-60$ & $1930-35$ & $1935-40$ & $1950-55$ & $1955-60$ & $1950-55$ & $1955-60$ \\
\hline U.S. & 0.144 & 0.167 & -0.167 & -0.184 & 0.049 & 0.009 & 0.072 & 0.016 \\
\hline Canada & 0.155 & 0.198 & -0.127 & -0.183 & -0.040 & -0.037 & 0.033 & 0.013 \\
\hline Australia & 0.102 & 0.097 & -0.184 & -0.185 & -0.085 & -0.077 & -0.013 & -0.022 \\
\hline New Zealand & 0.093 & 0.121 & -0.181 & -0.169 & 0.006 & 0.057 & 0.030 & 0.056 \\
\hline U.K. & -0.024 & 0.016 & -0.123 & -0.111 & -0.091 & -0.068 & -0.026 & -0.014 \\
\hline Germany & 0.006 & 0.065 & -0.137 & 0.087 & -0.314 & -0.119 & -0.172 & 0.017 \\
\hline France & 0.103 & 0.052 & -0.005 & -0.134 & -0.177 & -0.112 & -0.003 & 0.025 \\
\hline Netherlands & 0.039 & 0.045 & -0.084 & -0.121 & -0.152 & -0.081 & -0.021 & 0.026 \\
\hline Belgium & 0.060 & 0.100 & 0.009 & -0.081 & -0.111 & -0.102 & 0.040 & 0.015 \\
\hline Switzerland & 0.013 & 0.042 & -0.088 & -0.135 & -0.104 & -0.035 & -0.039 & 0.010 \\
\hline Italy & -0.071 & -0.042 & -0.004 & -0.003 & -0.264 & -0.177 & -0.106 & -0.034 \\
\hline Spain & -0.066 & 0.018 & 0.059 & -0.116 & -0.133 & -0.157 & 0.024 & -0.013 \\
\hline Portugal & -0.026 & 0.025 & 0.008 & -0.031 & -0.268 & -0.237 & -0.087 & -0.085 \\
\hline Denmark & 0.131 & 0.039 & -0.135 & -0.094 & -0.106 & -0.103 & -0.029 & -0.049 \\
\hline Norway & 0.068 & 0.056 & -0.184 & -0.189 & -0.061 & -0.066 & 0.024 & 0.002 \\
\hline Sweden & 0.014 & -0.025 & -0.172 & -0.128 & -0.029 & -0.016 & 0.001 & -0.007 \\
\hline Japan & -0.020 & -0.179 & 0.027 & -0.010 & -0.443 & -0.353 & -0.251 & -0.168 \\
\hline
\end{tabular}


Table A.8: Baby Busts and Baby Booms across Countries, No War

\begin{tabular}{|c|c|c|c|c|c|c|c|c|}
\hline \multirow[t]{2}{*}{ Country } & \multicolumn{2}{|c|}{$\widehat{C B R}_{1950 \mathrm{~s}}$} & \multicolumn{2}{|c|}{$\widehat{C B R}_{1930 s}$} & \multicolumn{2}{|c|}{$\widehat{G D P}_{1950 s}$, Linear } & \multicolumn{2}{|c|}{$\widehat{G D P}_{1950 s}, \mathrm{HP}$} \\
\hline & $1950-55$ & $1955-60$ & 1930-35 & $1935-40$ & $1950-55$ & $1955-60$ & $1950-55$ & $1955-60$ \\
\hline U.S. & 0.168 & 0.187 & -0.144 & -0.163 & 0.059 & 0.019 & 0.100 & 0.037 \\
\hline Canada & 0.189 & 0.228 & -0.104 & -0.158 & -0.038 & -0.035 & 0.034 & 0.013 \\
\hline Australia & 0.114 & 0.107 & -0.170 & -0.173 & -0.086 & -0.078 & -0.017 & -0.025 \\
\hline New Zealand & 0.128 & 0.150 & -0.166 & -0.147 & -0.003 & 0.048 & 0.009 & 0.038 \\
\hline U.K. & -0.035 & 0.009 & -0.137 & -0.126 & -0.089 & -0.066 & -0.021 & -0.009 \\
\hline Germany & -0.026 & 0.040 & -0.189 & 0.027 & -0.316 & -0.120 & -0.155 & 0.037 \\
\hline France & 0.105 & 0.058 & -0.047 & -0.160 & -0.243 & -0.180 & -0.170 & -0.112 \\
\hline Netherlands & 0.083 & 0.083 & -0.065 & -0.094 & -0.209 & -0.140 & -0.160 & -0.091 \\
\hline Belgium & 0.021 & 0.073 & -0.062 & -0.141 & -0.195 & -0.179 & -0.134 & -0.120 \\
\hline Switzerland & 0.025 & 0.054 & -0.101 & -0.139 & -0.140 & -0.071 & -0.110 & -0.049 \\
\hline Italy & -0.066 & -0.035 & -0.021 & -0.013 & -0.281 & -0.199 & -0.182 & -0.101 \\
\hline Spain & -0.073 & 0.012 & 0.046 & -0.126 & -0.147 & -0.170 & -0.013 & -0.042 \\
\hline Portugal & -0.016 & 0.034 & 0.013 & -0.024 & -0.298 & -0.267 & -0.168 & -0.150 \\
\hline Denmark & 0.180 & 0.079 & -0.126 & -0.073 & -0.138 & -0.133 & -0.103 & -0.106 \\
\hline Norway & 0.087 & 0.070 & -0.163 & -0.169 & -0.086 & -0.091 & -0.039 & -0.048 \\
\hline Sweden & 0.047 & 0.002 & -0.147 & -0.097 & -0.048 & -0.035 & -0.037 & -0.036 \\
\hline Japan & 0.053 & -0.126 & 0.080 & 0.052 & -0.449 & -0.361 & -0.286 & -0.200 \\
\hline
\end{tabular}


Table A.9: Impulse Response (in percent and levels), Parameter Sensitivity

\begin{tabular}{|c|c|c|c|c|c|c|c|c|c|c|}
\hline \multirow{2}{*}{$\begin{array}{l}\text { Cost } \\
\text { Type }\end{array}$} & \multicolumn{2}{|c|}{$\%$ Dev. } & \multicolumn{3}{|c|}{ CTFR Level } & \multicolumn{2}{|c|}{ \% Dev. } & \multicolumn{2}{|c|}{ CTFR Lev. } & \multirow{2}{*}{$\begin{array}{r}\text { Cost } \\
\text { (Rec.) }\end{array}$} \\
\hline & Init. & Lag. & Init. & Lag. & SS & Init. & Lag. & Init. & Lag. & \\
\hline \multicolumn{11}{|l|}{ Baseline } \\
\hline Goods & 1.74 & -1.56 & 2.31 & 2.24 & 2.27 & 1.74 & -1.56 & 2.31 & 2.24 & 0.193 \\
\hline Time & 1.04 & -0.94 & 2.30 & 2.25 & 2.27 & 1.04 & -0.94 & 2.30 & 2.25 & 0.193 \\
\hline Sensitivity & \multicolumn{5}{|c|}{ No Recalibration } & \multicolumn{5}{|c|}{ Recalibration } \\
\hline$\sigma=3.5$ & & & & & & & & & & \\
\hline Goods & 1.81 & -1.73 & 2.17 & 2.10 & 2.13 & 1.83 & -1.72 & 2.32 & 2.24 & 0.150 \\
\hline $\begin{array}{l}\text { Time } \\
\sigma=2.5\end{array}$ & 1.16 & -1.12 & 2.16 & 2.11 & 2.14 & 1.20 & -1.13 & 2.30 & 2.25 & 0.150 \\
\hline Goods & 1.66 & -1.36 & 2.52 & 2.44 & 2.48 & 1.66 & -1.41 & 2.31 & 2.24 & 0.246 \\
\hline $\begin{array}{l}\text { Time } \\
\beta=0.97^{20}\end{array}$ & 0.88 & -0.73 & 2.50 & 2.46 & 2.48 & 0.86 & -0.74 & 2.29 & 2.26 & 0.247 \\
\hline Goods & 1.68 & -1.40 & 2.47 & 2.40 & 2.43 & 1.65 & -1.40 & 2.31 & 2.24 & 0.242 \\
\hline $\begin{array}{l}\text { Time } \\
\beta=0.95^{20}\end{array}$ & 0.99 & -0.83 & 2.46 & 2.42 & 2.44 & 0.96 & -0.82 & 2.30 & 2.26 & 0.243 \\
\hline Goods & 1.81 & -1.75 & 2.15 & 2.08 & 2.12 & 1.82 & -1.70 & 2.32 & 2.24 & 0.151 \\
\hline $\begin{array}{l}\text { Time } \\
\gamma=1.026^{20}\end{array}$ & 1.09 & -1.06 & 2.14 & 2.10 & 2.12 & 1.11 & -1.04 & 2.30 & 2.25 & 0.152 \\
\hline Goods & 1.88 & -1.93 & 2.03 & 1.95 & 1.99 & 1.88 & -1.82 & 2.32 & 2.23 & 0.122 \\
\hline $\begin{array}{l}\text { Time } \\
\gamma=1.006^{20}\end{array}$ & 1.14 & -1.18 & 2.02 & 1.97 & 2.00 & 1.17 & -1.13 & 2.30 & 2.25 & 0.123 \\
\hline Goods & 1.61 & -1.25 & 2.63 & 2.55 & 2.59 & 2.22 & -2.38 & 2.32 & 2.22 & 0.294 \\
\hline $\begin{array}{l}\text { Time } \\
\sigma_{s}=0.08\end{array}$ & 0.94 & -0.73 & 2.62 & 2.57 & 2.59 & 1.29 & -1.48 & 2.30 & 2.24 & 0.295 \\
\hline Goods & 1.75 & -1.57 & 2.31 & 2.24 & 2.27 & 1.75 & -1.57 & 2.31 & 2.24 & 0.193 \\
\hline $\begin{array}{l}\text { Time } \\
\sigma_{s}=0.06\end{array}$ & 1.04 & -0.94 & 2.30 & 2.26 & 2.28 & 1.04 & -0.94 & 2.30 & 2.25 & 0.194 \\
\hline Goods & 1.74 & -1.57 & 2.31 & 2.23 & 2.27 & 1.74 & -1.56 & 2.31 & 2.24 & 0.191 \\
\hline $\begin{array}{l}\text { Time } \\
w^{2}=1.5\end{array}$ & 1.04 & -0.94 & 2.30 & 2.25 & 2.27 & 1.04 & -0.94 & 2.30 & 2.25 & 0.192 \\
\hline Goods & 1.84 & -1.88 & 2.33 & 2.25 & 2.29 & 1.83 & -1.87 & 2.32 & 2.23 & 0.198 \\
\hline $\begin{array}{l}\text { Time } \\
w^{2}=1\end{array}$ & 1.11 & -1.15 & 2.32 & 2.27 & 2.30 & 1.10 & -1.14 & 2.30 & 2.25 & 0.199 \\
\hline Goods & 1.61 & -1.21 & 2.28 & 2.22 & 2.25 & 1.61 & -1.20 & 2.31 & 2.25 & 0.186 \\
\hline $\begin{array}{l}\text { Time } \\
w^{2}=0.5\end{array}$ & 0.95 & -0.71 & 2.27 & 2.24 & 2.25 & 0.95 & -0.71 & 2.30 & 2.26 & 0.187 \\
\hline Goods & 1.29 & -0.51 & 2.23 & 2.19 & 2.21 & 1.30 & -0.51 & 2.30 & 2.26 & 0.176 \\
\hline Time & 0.73 & -0.29 & 2.23 & 2.20 & 2.21 & 0.73 & -0.29 & 2.29 & 2.27 & 0.177 \\
\hline
\end{tabular}

